\title{
Micro-hydration of a carbonyl group: how does the Molecular Electrostatic Potential (MESP) impact the formation of $(\mathrm{H} 2 \mathrm{O})_{\mathrm{n}}$ : $\left(\mathrm{R}_{2} \mathrm{C}=0\right)$ complexes ?
}

Emilie-Laure Zins

Sorbonne Université, CNRS, De la Molécule aux Nano-Objets: Réactivité, Interactions Spectroscopies, MONARIS, 75005, Paris, France

\section{Abstract}

The presence of a carbonyl group in a molecule usually leads to the identification of a $\pi$-hole in the molecular electrostatic potential (MESP) of the species. How does this electrophilic region influence the formation of micro-hydrated complexes? To address this point, we chose a panel of molecules with various MESPs, and we focused on several possible isomers for complexes containing one, two, three and six water molecules. Geometry optimizations and frequency calculations were carried out at the $L C-\omega P B E / 6-311++G(d, p)$ level, with the empirical correction GD3BJ for dispersion. The minima on the potential energy surfaces of the microhydrated complexes thus identified demonstrate that the MESP strongly modifies the geometry and stability of the isomers formed.

More precisely, the $\pi$-hole of carbonyl plays a decisive role in the formation of three-dimensional microhydrated isomers: whereas water-solutes interactions of the hydrogen bonding type mainly lead to structures in which the oxygen atoms of the water molecules are coplanar to the solute, this is not the case for $n \rightarrow \pi^{*}$ interactions involving one of the $\pi$-hole located near the carbon atom of the carbonyl. We show in this work that a MESP analysis complemented by an analysis of the contour maps of the Laplacian of the electron density $\nabla^{2} \rho$ of isolated solutes constitutes a good starting point to guide the chemist towards the identification of the most stable microhydrated isomers. This study also provides an interpretation of the most stable complex structures obtained after geometry optimization. We therefore suggest the introduction of electrophilicity and nucleophilicity scales as a first preliminary step in the search for geometries that would maximize interactions between complementary sites.

Key-words: $\pi$-hole, $\pi$-protrusion, microhydration, carbonyle, MESP, QTAIM, electrophilicity, nucleophilicity.

\section{Introduction}

The description, understanding, and prediction of non-covalent interactions between two partners constitutes a major issue for theoretical chemistry today. ${ }^{1}$ Many studies have shown the relevance of quantum chemistry interpretative tools such as to topology of the electron density $\rho$ (Quantum Theory of Atoms in Molecule, QTAIM), 2,3 the Electron Localization Function (ELF), ${ }^{4,5,6,7}$ the molecular electrostatic potential (MESP) $)^{8,9,10}$ or the Natural Bond Orbital (NBO) ${ }^{11}$ analysis for characterizing and understanding these interactions. ${ }^{12,13,14,15,16,17,18,19,20}$ In addition to orbital considerations, these 
studies have made it possible to better describe the electrostatic origin of interactions, which is at the origin of the geometry of the complexes obtained.

A precise understanding of the micro-hydration of small organic solute would allow shed some light on processes as important and as various as reactivity of atmospheric compounds, activation of small organic compounds in the interstellar media and biochemical recognition, amongst others. ${ }^{21}$ To predict the formation of small non-covalent complexes, a particularly simple methodological approach was proposed in line with the research carried out by Politzer, Murray and Clark. $^{22,23,24,25,26,27,28}$ This methodology is based on the identification of electrophilic and nucleophilic sites using the molecular electrostatic potential (MESP) plotted on an isosurface of electron density, prior to geometry optimization calculations.

One of the aspects of microhydration that remains poorly understood for small simple organic solutes is microhydration around pi-holes. In an analysis based on the MESPs, a pi-hole is a region orthogonal to a chemical bond where the electrostatic potential reaches a local (positive) maximum. Such regions are often observed in the surrounding of unsaturated chemical bonds such as $C=C$ and $\mathrm{C}=\mathrm{O}$. These unsaturated bonds are crucial in the reactivity of molecules of biological, atmospheric or astrochemical interest, among others. A description of their micro-hydration in order to study the understanding of possible activation (or inhibition) by water is thus crucial. In this work, we wanted to see for some simple cases, how a local variation of the MESP around a $\mathrm{C}=\mathrm{O}$ bond affects the formation of $\left(\mathrm{H}_{2} \mathrm{O}\right)_{1-3,6}:\left(\mathrm{R}_{2} \mathrm{CO}\right)$ complexes. The $\mathrm{R}$ substituents were chosen for the effect they caused on the pi-hole.

As pointed out by Politzer and Murray, ${ }^{29}$ the variation of the MESPs with the substituents "can be attributed in part to the electron-withdrawing or -donating tendency of the substituent, but more generally, VS(r) reflects not only the electronic density at $r$ but rather the total charge distributions of the electrons and nuclei in the molecule, including those of the substituent". ${ }^{30}$

Following the Hellman-Feynman theorem, the MESP can be used as a rule of thumb to look for noncovalent interactions, beyond the so-called "electrostatic interactions". 22,31,32 Interactions as various as $\mathrm{n} \rightarrow \pi^{*}$ and Burgi-Dunitz interactions, ${ }^{33,34,35} \mathrm{C}-\mathrm{H} \rightarrow \pi$ interactions, $^{36}$ and the so-called "unconventional $\mathrm{H}$-bonds" and virtually all the non-covalent interaction can be predicted and recovered using the MESP analysis. ${ }^{37}$ However, it should be noted that some care should be taken, especially for highly polarizable systems. In these cases, it is the MESP deformed by polarization that must be taken into account. ${ }^{38}$ In addition, in some cases, the choice of electronic isodensity on which the MESP is calculated should be adjusted. Indeed, the MESP is generally computed on an isosurface with an electron density of $0.001 \mathrm{e}$. bohr ${ }^{-3}$. This isosurface is considered to encompass more than $95 \%$ of the charge of the system, and to fit with the surface of the molecule. ${ }^{39}$ As a consequence, this isosurface can be assimilated to the surface of the molecule. ${ }^{39}$ Thus, the MESP plotted on this surface would correspond to the electrostatic potential experienced by the surrounding species. In some cases, however, we have shown that choosing a larger value, i.e. choosing an isosurface closer to the nucleus, makes it possible to better predict certain isomers involving weak non-covalent interactions. $^{23}$ 
We will therefore use here the MESP analysis of carbonyls and small aggregates $\left(\mathrm{H}_{2} \mathrm{O}\right)_{1-3,6}$ to identify the electrophilic and nucleophilic sites of isolated partners, predict the preferred directions of partners' approaches, optimize the structures of the complexes obtained, and characterize the noncovalent interactions of the complexes obtained via topological tools.

\section{Methodological approach}

\section{Computational details}

Herein, a three-step approach will be used to identify and characterize non-covalent interactions in the $\left(\mathrm{R}_{2} \mathrm{CO}\right)\left(\mathrm{H}_{2} \mathrm{O}\right)_{1-3}$ complexes:

> To begin with, a MESP analysis of the isolated partners makes it possible to identify qualitatively and quantitatively the electrophilic and nucleophilic zones of each partner. For this purpose, the total electrostatic potential is calculated on an electronic isodensity surface of $0.001 \mathrm{e} . \mathrm{bohr}^{-3}$. These calculations are performed using AIMStudio software, from.wfn files obtained after geometry optimization. ${ }^{40}$ The electrophilic (local maximum of MESPs) and nucleophilic (local minimum of MESPs) areas are then qualitatively and quantitatively identified.

At long distances, molecules orient themselves in a manner that maximizes interactions between complementary sites. This is why, based on the identification of the electrophilic sites and the nucleophilic sites of the isolated partners, one should try to orient both partners in such a way as to make the most electrophilic site of one partner interact with the most nucleophilic site of the other partner and vice-versa. It is also wise to look for approaches to create multiple interactions. All these structures are built and used as a starting point for a total optimization of geometry and frequency calculation. Thus, unlike other approaches, MESP analysis is only used as a guide to build complexes before total geometry optimization and frequency calculation. All calculations were performed with Gaussian09 software. ${ }^{41}$ The functional LC-wPBE ${ }^{42}$ was chosen because it proved to reproduce experimental data well for micro-hydrated complexes, in combination with the $6-311++G(d, p)$ base and the GD3BJ Grimme empirical correction. ${ }^{43,23,44,45}$ The convergence options scf=Tight and Int=UltraFine were also used. The.wfn files needed for topological characterization were generated during this step. To complement this approach, and to confirm its relevance in this case, all the minima obtained for a microhydrated complex with a carbonyl A and not with a carbonyl B were used as a starting point, after modification of the substituents, for the corresponding microhydrated complex with carbonyl B. It is interesting to note that none of these calculations led to new minima (except for ketoenolic isoremizations, which will be discussed in the section on di-hydrated complexes). Thus, any structure that did not correspond to the pooling of complementary sites on the partners' MESP proved to be unfavourable in terms of energy, at the chosen calculation level.

For all the optimized structures corresponding to local minima, a topological characterization based on the QTAIM approach was performed using the AIMStudio software. ${ }^{40}$

To compare complexes involving a different solute, and water molecules interacting separately or as a cluster, an interaction energy $E_{\text {int }}$ was calculated, with respect to all isolated partners for each $\left(\mathrm{H}_{2} \mathrm{O}\right)_{n}:\left(\mathrm{R}_{2} \mathrm{CO}\right)$ complex as follows: 


$$
\mathrm{E}_{\text {int(H2O)n:(R2CO) }}=\mathrm{E}_{(\mathrm{H} 2 \mathrm{O}) \mathrm{n}:(\mathrm{R} 2 \mathrm{CO})}-\left(\mathrm{E}_{(\mathrm{R} 2 \mathrm{CO})}+n \times \mathrm{E}_{(\mathrm{H} 2 \mathrm{O})}\right)
$$

For the sake of clarity, the different complexes will be named as follows: $W_{x_{-}}^{\lambda} y_{\text {, }}$ where $\mathrm{x}$ is the number of water molecules in the complex, $\mathrm{y}$ is the order by decreasing interaction energy (in absolute value) and $\lambda=\mathrm{H}, \mathrm{F}, \mathrm{Cl}, \mathrm{NC}$ or $\mathrm{H}_{2} \mathrm{C}$, correspond to the $\mathrm{H}_{2} \mathrm{CO}, \mathrm{Cl}_{2} \mathrm{CO}, \mathrm{F}_{2} \mathrm{CO},(\mathrm{NC})_{2} \mathrm{CO}, \mathrm{H}_{2} \mathrm{C}=\mathrm{CO}$ solutes. Thus, the notation $W_{1}^{N C}{ }_{-} 1$ corresponds to the monohydrated complex characterized by the highest water-solute interaction energy (in absolute value), it is the most stable isomer of the $\left(\mathrm{H}_{2} \mathrm{O}\right):(\mathrm{NC})_{2} \mathrm{CO}$ complex.

All the Cartesian Coordinates of the optimized complexes herein discussed are presented in Supporting Information.

\section{Characterization of the electrophilic and nucleophilic features of isolated partners}

It was previously suggested that a quantitative comparison of electrophilic and nucleophilic sites on a solute with those available on water clusters seems to provide interesting clues regarding how water / solute interactions can occur: the presence of a more electrophilic or nucleophilic site on the solute compared to water clusters could lead to their dissociation; otherwise, a segregation of water molecules seems more favourable. This is why we propose here to introduce a nucleophilicity scale and an electrophilicity scale to compare microhydration around the molecules $\mathrm{H}_{2} \mathrm{CO}, \mathrm{Cl}_{2} \mathrm{CO}, \mathrm{F}_{2} \mathrm{CO}$, $(\mathrm{NC})_{2} \mathrm{CO}$ and $\mathrm{H}_{2} \mathrm{C}=\mathrm{CO}$.

None of the selected solute contains a more nucleophilic site than the oxygen atoms of the water molecules (Figure 1).

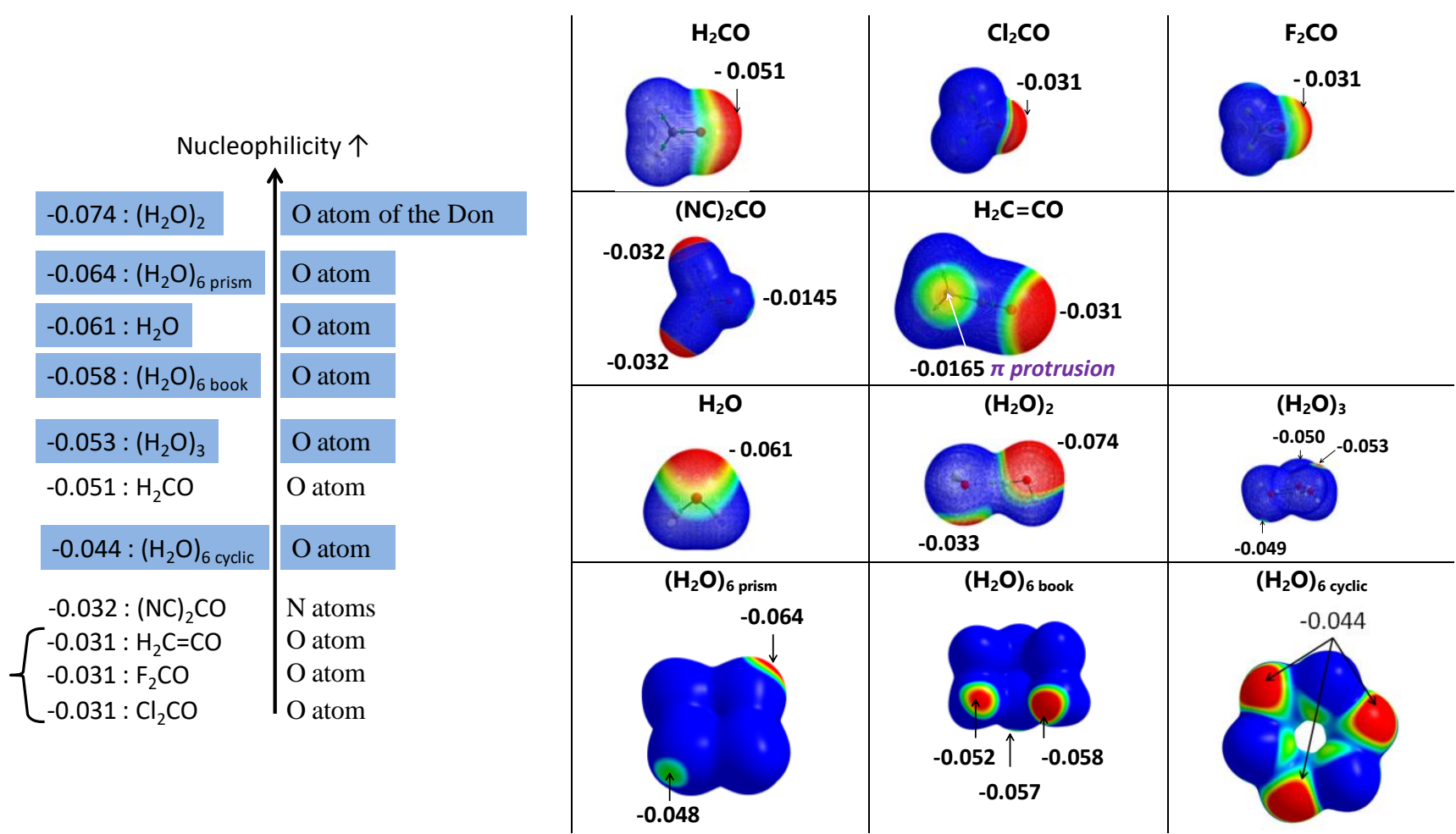

Figure 1: MESP analysis of the nucleophilic sites available in the different partners considered for this study. Left: proposed nucleophilicity scale by comparing the values of the different nucleophilic sites identified by the MESP analysis. Right: identification of nucleophilic sites according to the MESP values represented on an isodensity surface $\rho=0.001 \mathrm{e}$. bohr $^{-3}$; the values are in a.u., 1 a.u. $=627.5 \mathrm{kcal} / \mathrm{mol}$. 
In the $\mathrm{H}_{2} \mathrm{CO}, \mathrm{H}_{2} \mathrm{CCO}, \mathrm{Cl}_{2} \mathrm{CO}$ and $\mathrm{F}_{2} \mathrm{CO}$ molecules, the most nucleophilic site of the solute is located around the oxygen atom, in the axis of the $\mathrm{C}=\mathrm{O}$ bond. It is the only nucleophilic site available on $\mathrm{H}_{2} \mathrm{CO}, \mathrm{Cl}_{2} \mathrm{CO}$ and $\mathrm{F}_{2} \mathrm{CO}$ solutes. In the case of the $\mathrm{H}_{2} \mathrm{CCO}$ molecule, two other secondary nucleophilic sites are located near the $\mathrm{sp}^{2}$ hybrid carbon, perpendicular to the $\mathrm{C}=\mathrm{C}$ bond, on either side of the plane of the molecule. In the case of the molecule $(\mathrm{NC})_{2} \mathrm{CO}$, the main nucleophilic sites are carried by the nitrogen atoms, and are located in the axis of the $\mathrm{CN}$ bonds. For this molecule, the oxygen atom is only a secondary nucleophilic site.

The next step is to consider electrophilic sites (Figure 2). The $(\mathrm{NC})_{2} \mathrm{CO}, \mathrm{F}_{2} \mathrm{CO}$ and $\mathrm{Cl}_{2} \mathrm{CO}$ molecules have a pi-hole located in the vicinity of the carbon $\mathrm{sp}^{2}$ hybridised. For the $(\mathrm{NC})_{2} \mathrm{CO}$ and $\mathrm{F}_{2} \mathrm{CO}$ molecules, the electrophilicity of this pi-hole is comparable to that of the $\mathrm{H}$ atoms of the water molecule, but remains lower than that of the most electrophilic sites of the water dimer. In the case of the $\mathrm{Cl}_{2} \mathrm{CO}$ molecule, in addition to this pi-hole, two sigma-holes are also present, at the level of the chlorine atoms, in the axis of the $\mathrm{C}-\mathrm{Cl}$ bonds.

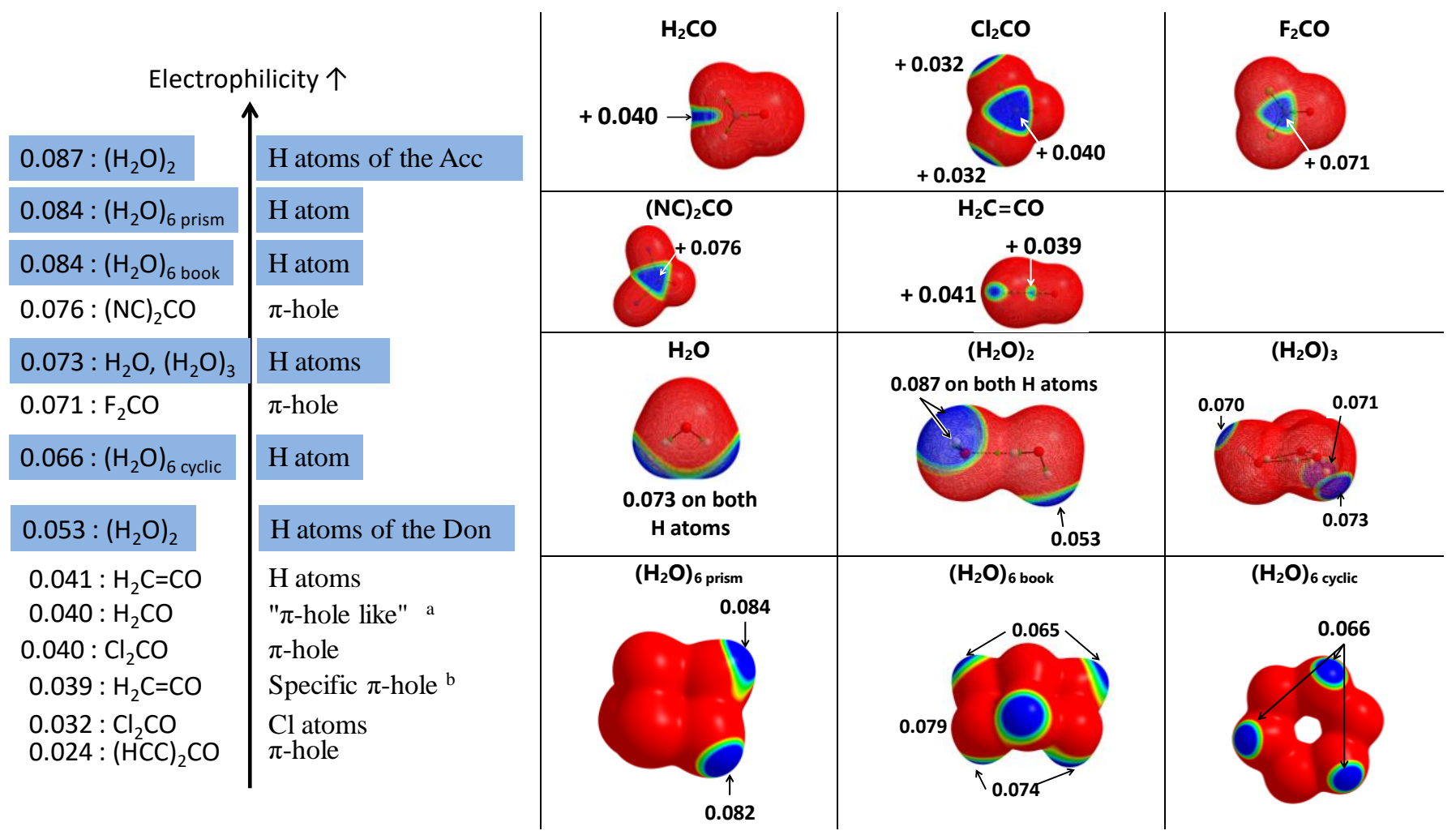

Figure 2: MESP analysis of the electrophilic sites available in the different partners considered for this study. Left: proposed electrophilicity scale by comparing the values of the different electrophilic sites identified by the MESP analysis. Right: identification of electrophilic sites according to the MESP values represented on an isodensity surface $\rho=0.001 \mathrm{e} . \mathrm{bohr}^{-3}$; the values are in a.u., $1 \mathrm{a} . \mathrm{u} .=627.5 \mathrm{kcal} / \mathrm{mol}$.

The $\mathrm{H}_{2} \mathrm{CO}$ molecule does not strictly speaking contain pi-hole at the level of the $\mathrm{sp}^{2}$ hybrid carbon, but rather a kind of "electrophilic belt" in the axis of the $\mathrm{C}=\mathrm{O}$ bond, in the direction opposite to the oxygen atom. However, the contour maps of the Laplacian of the electron density $\nabla^{2} \rho$ shows a region of low electron density near the carbonyl carbon atom, in a plane orthogonal to the molecule (Figure 2). This feature is qualitatively comparable to the contour maps in the vicinity of the carbon atom in the molecule $(\mathrm{NC})_{2} \mathrm{CO}$. Such features of the electron density $\nabla^{2} \rho$ are considered to be complementary to the MESP analysis for the identification of $\pi$-holes. Thus: 
$>$ the MESP analysis leads to the identification of a $\pi$-hole located in the vicinity of the carbon $\mathrm{sp}^{2}$ hybridised, in the case of the $(\mathrm{NC})_{2} \mathrm{CO}, \mathrm{F}_{2} \mathrm{CO}$ and $\mathrm{Cl}_{2} \mathrm{CO}$ molecules,

$>$ the contour maps of the Laplacian of the electron density $\nabla^{2} \rho$ also suggests the presence of a pihole located in the vicinity of the carbon $\mathrm{sp}^{2}$ hybridised, in the case of the $\mathrm{H}_{2} \mathrm{CO}$ molecule.

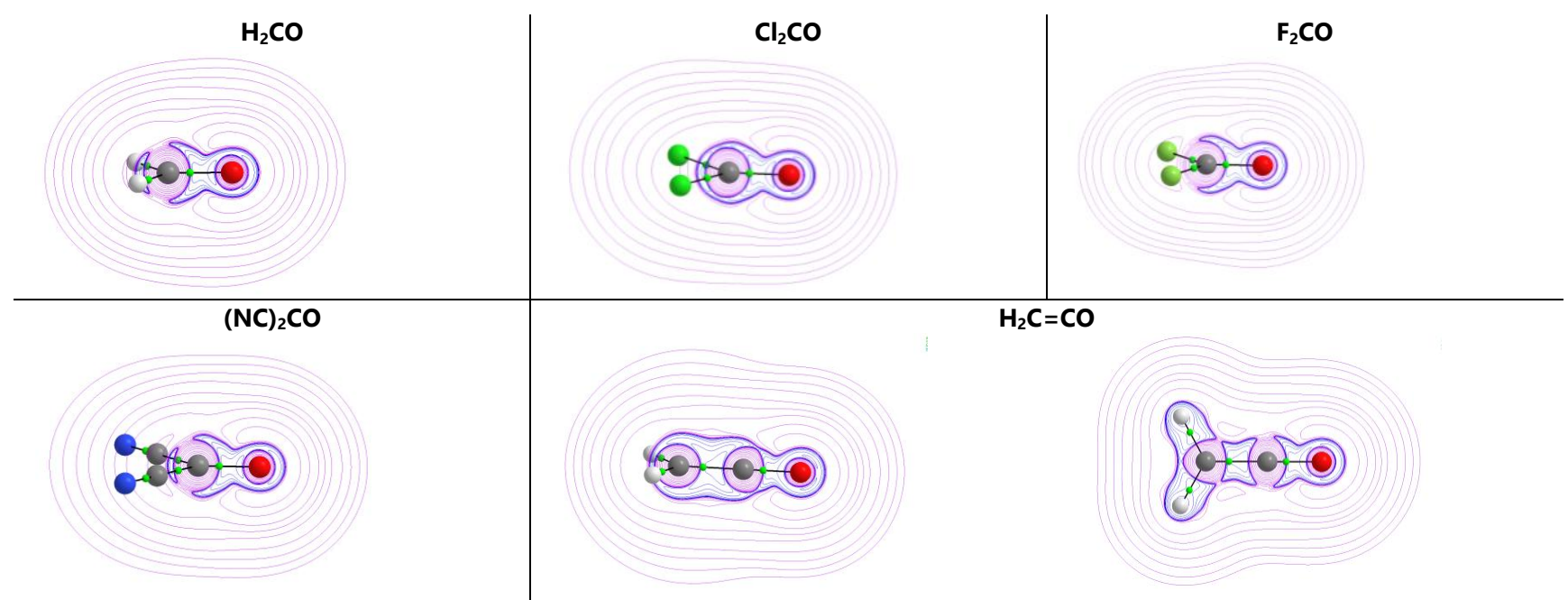

Figure 3: Contour map of the Laplacian of the electron density $\nabla^{2} \rho$ orthogonally to the plane of the molecule $\left(\mathrm{H}_{2} \mathrm{CO}, \mathrm{Cl}_{2} \mathrm{CO}, \mathrm{F}_{2} \mathrm{CO},(\mathrm{NC})_{2} \mathrm{CO}\right.$ and $\mathrm{H}_{2} \mathrm{C}=\mathrm{CO}$ left $)$ and in the plane of the molecule $\left(\mathrm{H}_{2} \mathrm{C}=\mathrm{CO}\right.$, right). The blue lines correspond to negative values of $\nabla^{2} \rho$ whereas red lines correspond to positive values of $\nabla^{2} \rho$. The dark lines and the small green spheres are the bond paths and the bond critical points (BCP), respectively.

Furthermore, the MESP analysis of the $\mathrm{H}_{2} \mathrm{CCO}$ molecule leads to the identification of two $\pi$-holes, symmetrical and perpendicular to the $\mathrm{C}=\mathrm{O}$ bond; it is worth underlying that these $\pi$-holes are located in the plane of the molecule, and not perpendicular to it as is the case in the other carbonyls herein considered. This is confirmed by the contour maps of the Laplacian of the electron density $\nabla^{2} \rho$ (Figure 3): the region of low electron density is located perpendicular to the axis of the $C=O$ link. The contour maps of the Laplacian of the electron density $\nabla^{2} \rho$ of the $\mathrm{H}_{2} \mathrm{CCO}$ molecule also leads to the identification of a egion of highest electron density in the vicinity of the $\mathrm{C}=\mathrm{C}$ bond, above and below the plane of the molecule.

Thus, these five molecules containing a carbonyl function $\mathrm{C}=\mathrm{O}$ and 2 to 4 other atoms are associated to a diversity of MESPs. We will therefore investigate how one, two, three or six water molecules can interact with these solutes.

\section{Results}

\section{1-1 isomers}

Based on the MESPs, our approach led to the identification of 11 monohydrate complexes. The interaction energies of the various complexes obtained are presented in Figure 4. More precisely, all the structures obtained, together with their QTAIM topological characterization of non-covalent interactions, are presented in Table 1, as well as in Supporting Information. 


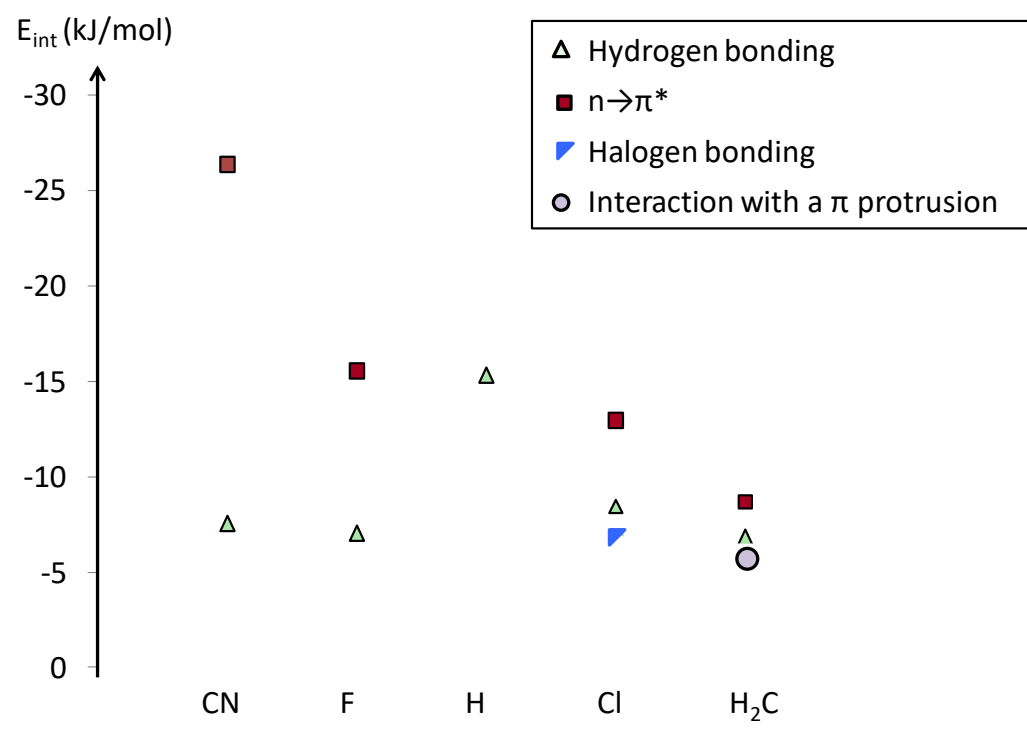

Figure 4: Comparison of the water-solute interaction energies in the most stable $\left(\mathrm{H}_{2} \mathrm{O}\right): \mathrm{S}$ isomers obtained after geometry optimization (including ZPE). 


\begin{tabular}{|c|c|c|c|}
\hline & $\mathrm{H}_{2} \mathrm{CO}$ & $\mathrm{Cl}_{2} \mathrm{CO}$ & $\mathrm{F}_{2} \mathrm{CO}$ \\
\hline $\begin{array}{l}\text { Hydrogen } \\
\text { bonding }\end{array}$ & $\begin{aligned} & \rho=0.022 \\
& \nabla^{2} \rho=+0.08 \\
& \varepsilon=0.03\end{aligned}$ & $\begin{aligned} \dot{C}_{\rho}=0.015 \\
\nabla^{2} \rho=+0.06 \\
\varepsilon=0.04\end{aligned}$ & $\begin{aligned} \rho & =0.014 \\
\nabla^{2} \rho & =+0.06 \\
\varepsilon & =0.04\end{aligned}$ \\
\hline $\begin{array}{l}\quad \mathrm{n} \rightarrow \pi \\
\text { interactions }\end{array}$ & & $\begin{aligned} \rho & =0.011 \\
\nabla^{2} \rho & =+0.04 \\
\varepsilon & =0.15\end{aligned}$ & $\begin{aligned} \rho & =0.015 \\
\nabla^{2} \rho & =+0.06 \\
\varepsilon & =0.10\end{aligned}$ \\
\hline & & $W_{1}^{C l}{ }_{1}^{C} \quad E_{\text {int }}=-12.93 \mathrm{~kJ} / \mathrm{mol}$ & $W_{1-}^{F} 2 \quad \mathrm{E}_{\text {int }}=-15.52 \mathrm{~kJ} / \mathrm{mol}$ \\
\hline $\begin{array}{c}\text { Other } \\
\text { interactions }\end{array}$ & & $\begin{aligned} \uparrow & \uparrow \\
\rho & =0.010 \\
\nabla^{2} \rho & =+0.04 \\
\varepsilon & =0.15 \\
W_{1}^{C l} 9 \quad E_{\text {int }} & =-7.00 \mathrm{~kJ} / \mathrm{mol}\end{aligned}$ & \\
\hline
\end{tabular}

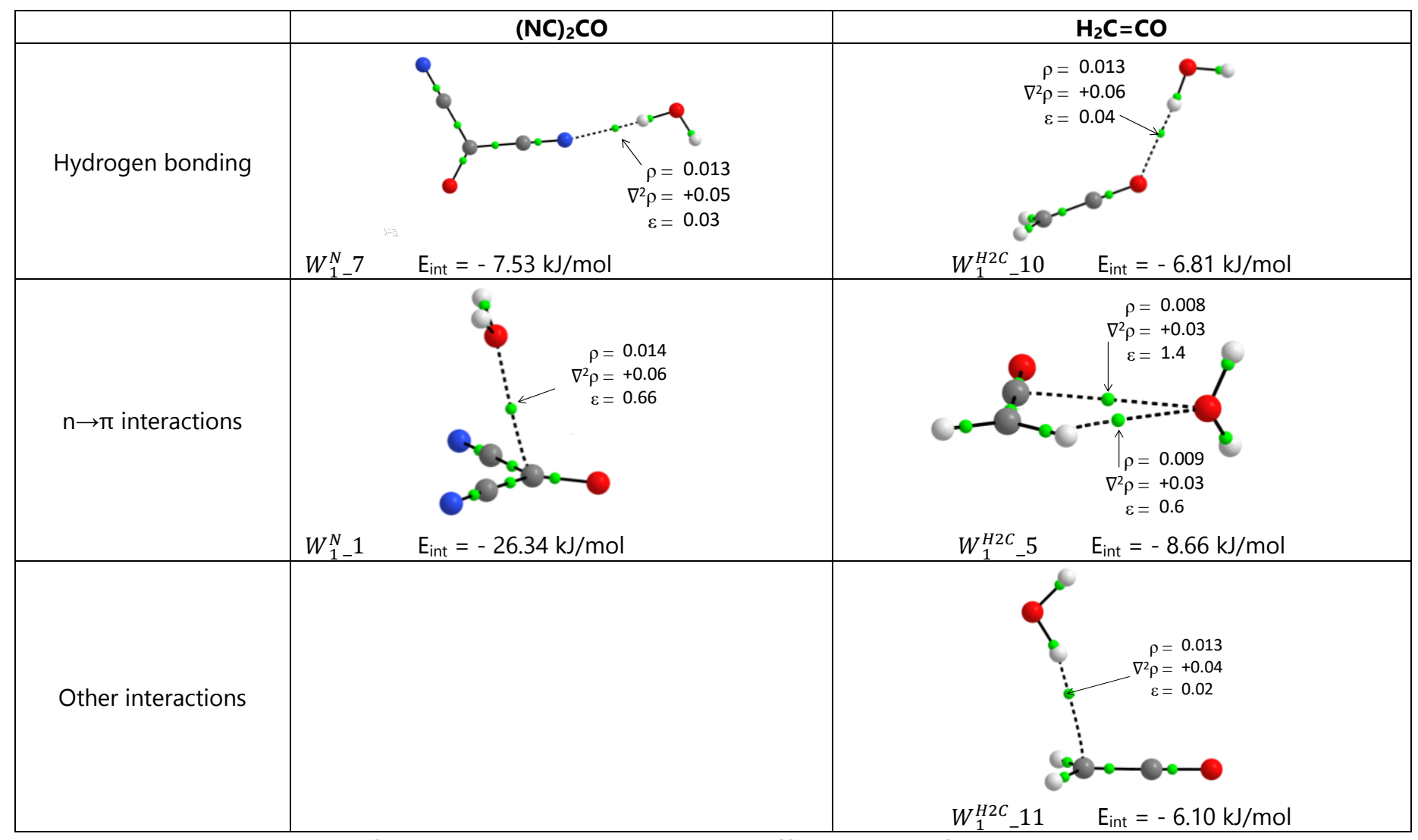

Table 1: Characterization of non-covalent interactions in the different types of monohydrated complexes obtained after geometry optimization at the LC- $\omega P B E / 6-311++G(d, p)$ level, with GD3BJ correction. The dark lines and the small green spheres are the bond paths and the bond critical points (BCP), respectively. For the intermolecular $B C P s$, the electron density $\rho$, the Laplacian of the electron density $\nabla^{2} \rho$ and the ellipticity $\varepsilon$ are given. 
Complexes in which one of the hydrogen atoms of the water molecule acts as a hydrogen bond donor to the oxygen atom of the carbonyl function are obtained, with four of the five solutes investigated here: $\mathrm{H}_{2} \mathrm{CO}, \mathrm{Cl}_{2} \mathrm{CO}, \mathrm{H}_{2} \mathrm{C}=\mathrm{CO}$ and $\mathrm{F}_{2} \mathrm{CO}$. It is interesting to examine how nucleophilicity around the oxygen atom of the carbonyl group of the isolated solute influences the energy of water-solute interaction in these complexes (Table 2).

\begin{tabular}{|c|c|c|}
\hline & $\begin{array}{c}\text { Minimum value of the MESP (in a.u.) around the } \\
\text { oxygen atom of the carbonyl group in the } \\
\text { isolated solute }\end{array}$ & $\begin{array}{c}\mathrm{E}_{\text {int }} \text { (in } \mathrm{kJ} / \mathrm{mol} \text { ) in the hydrogen } \\
\text { bonded type complex }\end{array}$ \\
\hline $\mathrm{H}_{2} \mathrm{CO}$ & -0.051 & -15.30 \\
\hline $\mathrm{Cl}_{2} \mathrm{CO}$ & -0.031 & -8.42 \\
\hline $\mathrm{H}_{2} \mathrm{CCO}$ & -0.031 & -7.02 \\
\hline $\mathrm{F}_{2} \mathrm{CO}$ & -0.031 & -6.81 \\
\hline
\end{tabular}

Table 2: Comparison of the nucleophilicity of the oxygen atom of the carbonyl group of the isolated solute with the energy of water-solute interaction in complexes involving hydrogen bond interaction.

In the case of $(\mathrm{NC})_{2} \mathrm{CO}$ solute, the hydrogen bond interaction is not with the oxygen atom of the solute, but with one of the nitrogen atoms. This result is consistent with the MESP of the isolated solute: the nucleophilicity of the nitrogen atoms is higher than that of the oxygen atom, for this solute.

Monohydrated isomers involving the formation of interactions $n \rightarrow \pi$ are also observed with four of the five isomers selected for this study: $(\mathrm{NC})_{2} \mathrm{CO}, \mathrm{F}_{2} \mathrm{CO}, \mathrm{Cl}_{2} \mathrm{CO}$, and $\mathrm{H}_{2} \mathrm{C}=\mathrm{CO}$. Again, it is interesting to compare the properties of isolated solutes, and in particular the value of MESP in the vicinity of the $\pi$-hole, with the interaction energy in these complexes (Table 3)

\begin{tabular}{|c|c|c|}
\hline & $\begin{array}{c}\text { Maximum value of the MESP (in a.u.) around the } \\
\pi \text {-hole for the isolated solute }\end{array}$ & $\begin{array}{c}\mathrm{E}_{\mathrm{int}} \text { (in } \mathrm{kJ} / \mathrm{mol} \text { ) in the } \mathrm{n} \rightarrow \pi \text { type } \\
\text { complex }\end{array}$ \\
\hline$(\mathrm{NC})_{2} \mathrm{CO}$ & 0.076 & -26.34 \\
\hline $\mathrm{F}_{2} \mathrm{CO}$ & 0.071 & -15.52 \\
\hline $\mathrm{Cl}_{2} \mathrm{CO}$ & 0.040 & -12.93 \\
\hline $\mathrm{H}_{2} \mathrm{CCO}$ & 0.039 & -8.66 \\
\hline $\mathrm{H}_{2} \mathrm{CO}$ & Pas de vrai $\pi$-hole & \\
\hline
\end{tabular}

Table 3: Comparison of the electrophilicity of the $\pi$-hole for the isolated solute with the energy of water-solute interaction in complexes involving $\mathbf{n} \rightarrow \boldsymbol{\pi}$ type interaction.

The use of the MESP of the isolated partners makes it possible to better guide the chemist in the initial structures to be built before optimization. In order to determine the qualitative or quantitative nature of the relationship between the MESP of the solute and the resulting monohydrate complex (geometry and structure), we plotted variations in intermolecular interaction energy as a function of the MESP value at the electrophilic or nucleophile site of the isolated solute involved in the interaction. To take into account the electrophilic or nucleophilic nature of the olute, and therefore the sign of MESP, we multiplied the interaction energy by 1 for interactions with electrophilic sites of the solute, and by $(-1)$ for interactions with nucleophilic sites of the solute. The graph presented in Figure 5 suggests a quantitative linear relationship between the MESP of the isolated solute and the interaction energy of a water molecule with this solute site. 


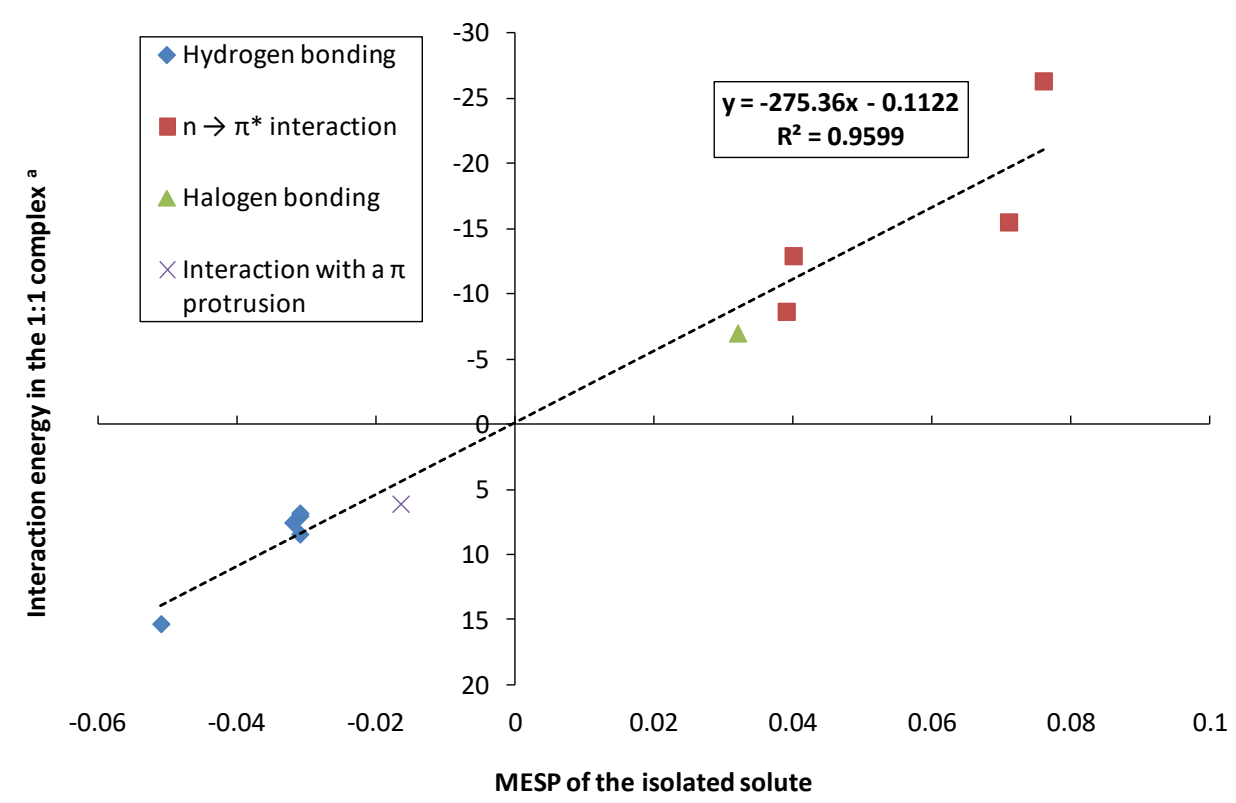

Figure 5: Variations of water-solute interaction energy in $\left(\mathrm{H}_{2} \mathrm{O}\right): \mathrm{S}$ complexes as a function of the MESP value (in a.u.) of the solute site involved in the interaction. a: To account for the electrophilic or nucleophilic nature of the solute, the values of the interaction energy have been multiplied by $(-1)$ for interactions with a nucleophilic site of the solute.

\section{1-2 isomers}

In the search for dihydrate complexes, the starting structures were obtained by seeking to maximize interactions between a monohydrate complex and a water molecule, or between an isolated carbonyl and a water dimer. Finally, after geometry optimization, 11 dihydrate complexes were obtained. These complexes can be classified according to the nature of carbonyl, the nature of the main water-solute interaction (hydrogen bond versus $n \rightarrow \pi^{*}$ interaction), and the interaction energy, as shown in Figure 6.

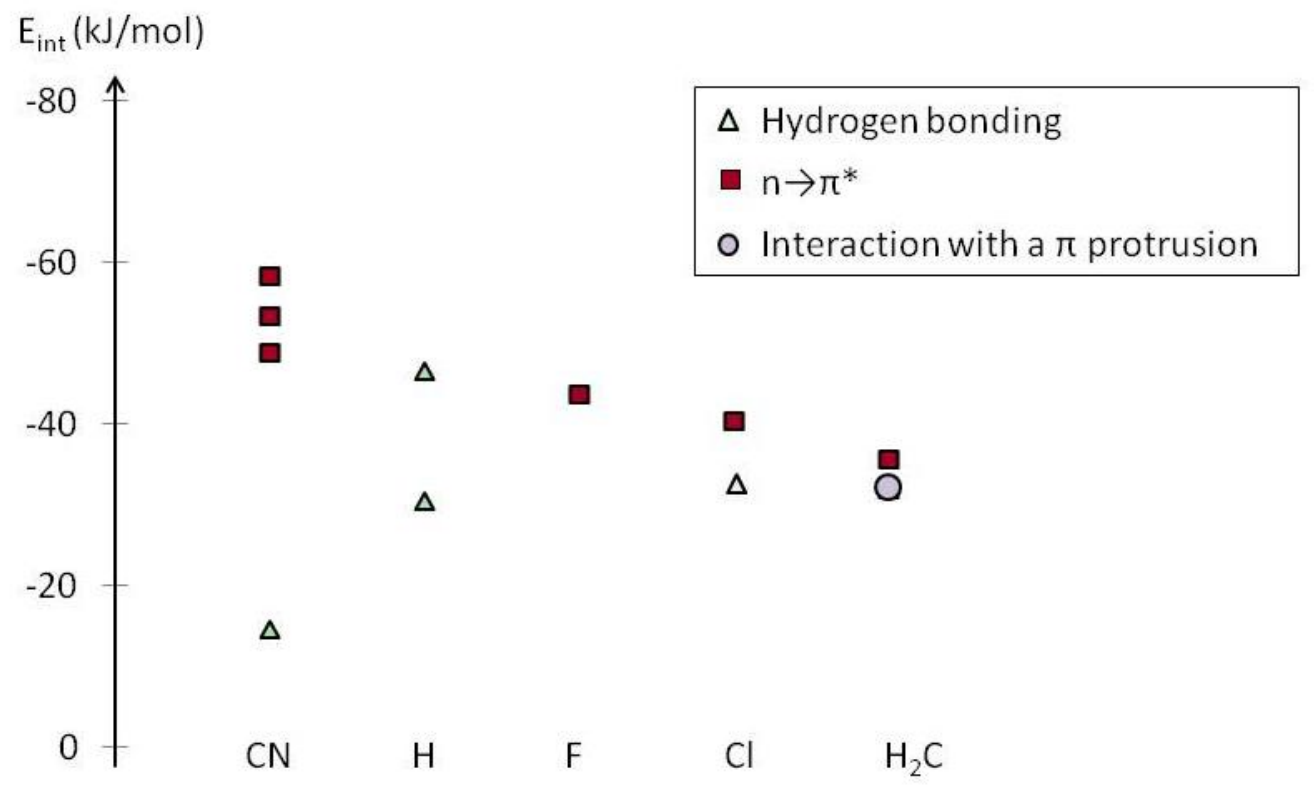

Figure 6: Comparison of the water-solute interaction energies in the most stable $\left(\mathrm{H}_{2} \mathrm{O}\right)_{2}: \mathrm{S}$ isomers obtained after geometry optimization (including ZPE). The water-solute interaction energy is calculated with respect to the sum of twice the energy of an isolated water molecule and the energy of the isolated solute. 
It is interesting to look in more detail into the nature of the water-solute interactions in these complexes, and to try to link it to the MESPs of isolated carbonyls. To this end, we will detail the results presented in Figure 6 and Table 2, using the electrophilicity and nucleophilicity scales of the isolated partners presented in Figures 1 and 2 .

Among all the $\left(\mathrm{H}_{2} \mathrm{O}\right)_{2}$ :Scomplexes, the three with the highest energy of complexation involve a $n \rightarrow \pi^{*}$ interaction between the $\pi$-hole of $(\mathrm{NC})_{2} \mathrm{CO}$ and at least one oxygen atom of a water molecule (complexes $W_{2}^{N C}{ }_{\_} 1, \mathrm{E}_{\text {int }}=-58.44 \mathrm{~kJ} / \mathrm{mol}, W_{2}^{N C}{ }_{-} 2, \mathrm{E}_{\text {int }}=-53.32 \mathrm{~kJ} / \mathrm{mol}$ et $W_{2}^{N C}{ }_{-} 3, \mathrm{E}_{\text {int }}=-48.84 \mathrm{~kJ} / \mathrm{mol}$ ). The two most stable isomers involve the water dimer interacting with the solute, while in the $W_{2}^{N C}{ }_{-} 3$ isomer, the two water molecules are located symmetrically with respect to the solute plane, each interacting with one of the two $\pi$-holes.

The fourth dihydrated complex in order of interaction energy is the $W_{2}^{H}{ }_{-} 4$ complex $\left(E_{\text {int }}=-46.54\right.$ $\mathrm{kJ} / \mathrm{mol}$.) : it is a complex formed between the water dimer and $\mathrm{H}_{2} \mathrm{CO}$. The QTAIM analysis shows that this isomer involves the formation of two hydrogen bond interactions between water and solute: two hydrogen bond interactions. The strongest of these interactions is characterized by an electron density comparable to that between the two water molecules. This complex involves one of the most nucleophilic sites among all the carbonyls considered in this study. Moreover, in the absence of a real $\pi$-hole on the isolated solute, obtaining a flat structure for the dihydrate complex is not surprising. 


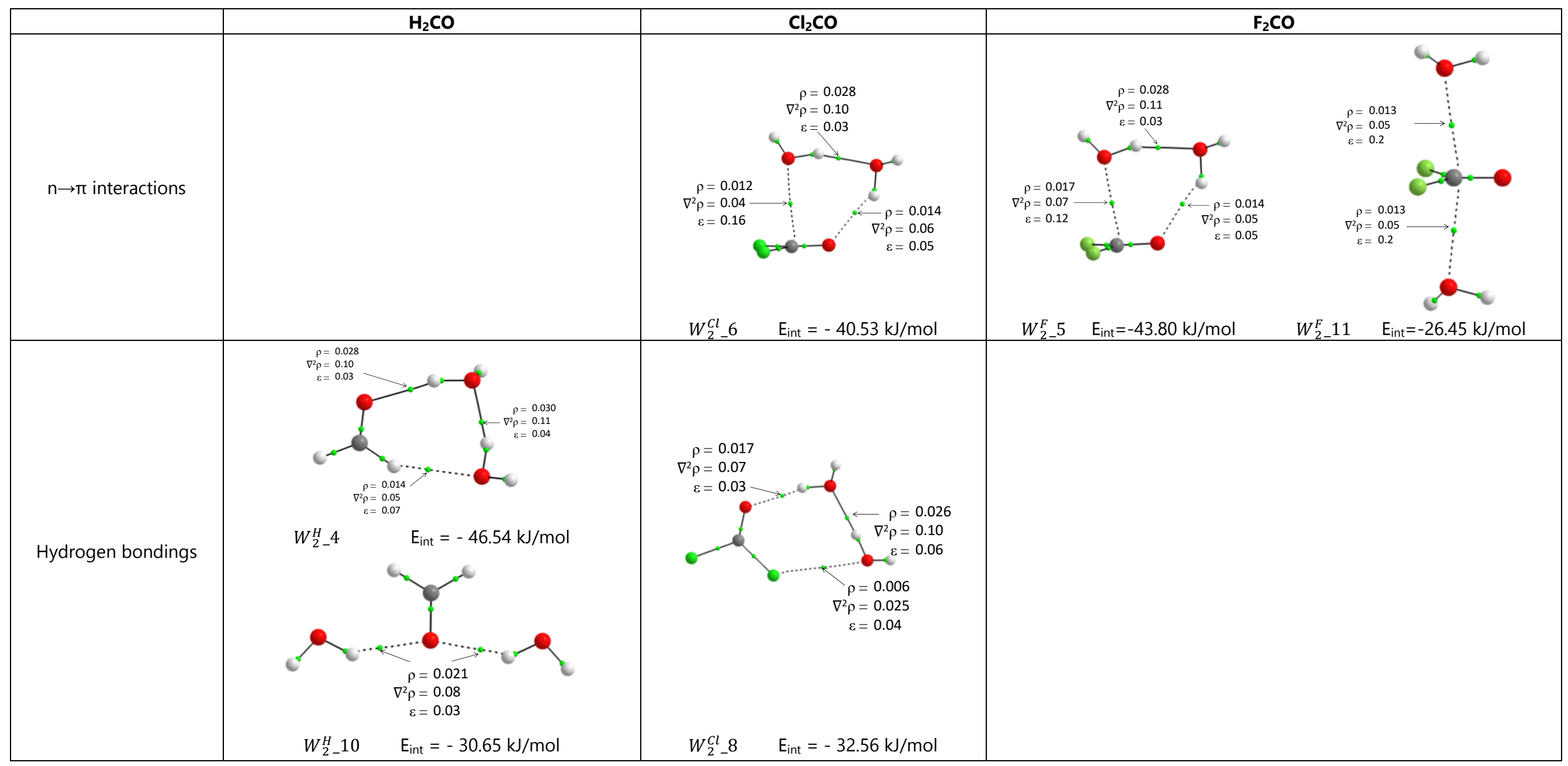




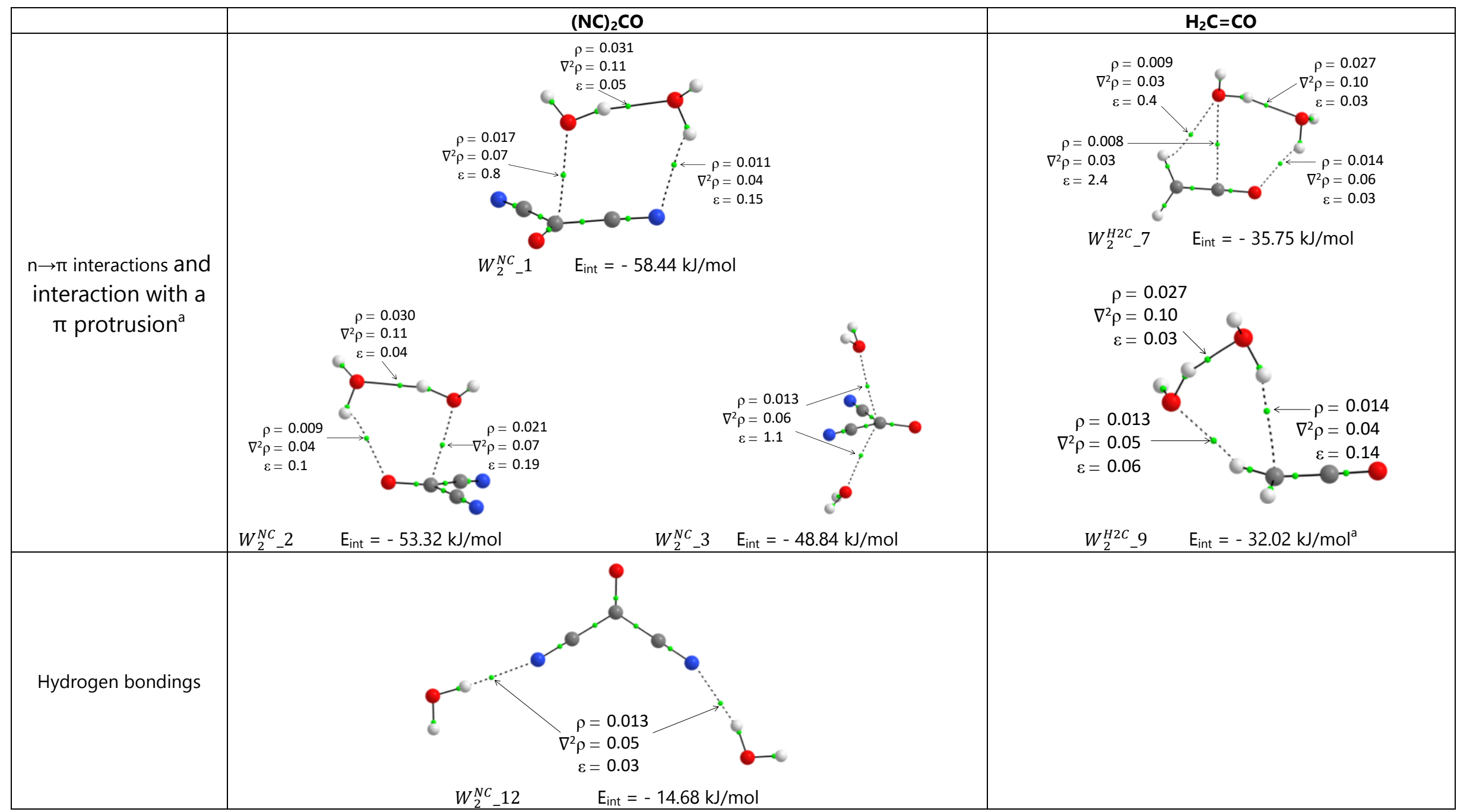

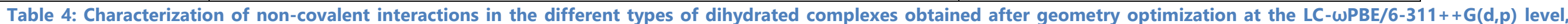

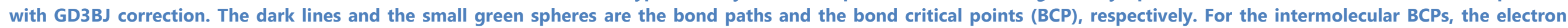

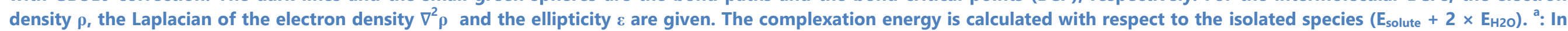
this complex, a water molecule interacts with the solute via the $\pi$ protrusion located above the carbon hybridised sp $^{2}$. 
Two other dihydrated complexes with a complexing energy very close to $W_{2}^{H}{ }_{-} 4$ are obtained in the order of decreasing complexation energy: $W_{2 \_}^{F} 5\left(\mathrm{E}_{\mathrm{int}}=-43.80 \mathrm{~kJ} / \mathrm{mol}\right.$.), and $W_{2}^{C l}{ }_{-} 6\left(\mathrm{E}_{\text {int }}=-40.53\right.$ $\mathrm{kJ} / \mathrm{mol}$.). For these two complexes, the water dimer is placed perpendicular to the carbonyl $\mathrm{F}_{2} \mathrm{CO}$ and $\mathrm{Cl}_{2} \mathrm{CO}$, respectively, and the QTAIM analysis shows that the water dimer forms two interactions with the solute: a hydrogen bond interaction and a $n \rightarrow \pi^{*}$ interaction with the solute $\pi$-hole. The QTAIM analysis also shows that the interaction with the $\pi$-hole of the solute is slightly more pronounced in the case of $\mathrm{F}_{2} \mathrm{CO}$ solute than in the case of $\mathrm{Cl}_{2} \mathrm{CO}$. Again, these results are quite consistent with the MESP analyses of the isolated partners: $\pi$-hole of the isolated $\mathrm{F}_{2} \mathrm{CO}$ solute is more electrophilic than $\pi$-hole of the $\mathrm{Cl}_{2} \mathrm{CO}$ solute.

Two complexes close in energy are obtained with the $\mathrm{H} 2 \mathrm{CCO}$ solute: $W_{2}^{\mathrm{H} 2 \mathrm{C}}{ }_{7} \quad\left(\mathrm{E}_{\text {int }}=-35.75 \mathrm{~kJ} / \mathrm{mol}\right.$.) and $W_{2}^{H 2 C} \_9 \quad\left(\mathrm{E}_{\text {int }}=-32.02 \mathrm{~kJ} / \mathrm{mol}\right.$.) These two complexes involve a water dimer interacting with the solute. The QTAIM analysis shows that, in the $W_{2}^{H 2 C}{ }_{-} 7$ complex, the water dimer interacts with the $\pi$ hole of the solute, which is located in the plane of the molecule, unlike most of the $\pi$-holes. Two other water-solute interactions, of the hydrogen bond type, are also identified in this complex. In the $W_{2}^{H 2 C}{ }_{-} 9$ complex, the water dimer interacts with the solute via the $\pi$-protrusion and one of the hydrogen atoms of the $\mathrm{CH}_{2}$ group.

The other dihydrated complex that have been obtained after geometry optimization are energetically less favourable:

$>$ In the $W_{2}^{C l}{ }_{-} 8$ complex $\left(E_{\text {int }}=-32.56 \mathrm{~kJ} / \mathrm{mol}\right.$.), the water dimer does not interact with the $\pi$ hole of the solute, but with the oxygen atom via a hydrogen bond, and one of the chlorine atoms via a halogen interaction.

$>$ In the $W_{2 \_}^{H} 10 \quad\left(\mathrm{E}_{\text {int }}=-30.72 \mathrm{~kJ} / \mathrm{mol}\right.$.), $W_{2 \_}^{F} 11\left(\mathrm{E}_{\text {int }}=-26.45 \mathrm{~kJ} / \mathrm{mol}\right.$.) and $W_{2 \_}^{N} 12\left(\mathrm{E}_{\text {int }}=-14.68\right.$ $\mathrm{kJ} / \mathrm{mol}$.) complexes, the two water molecules interact separately with one of the most nucleophilic sites of the solution.

With the $(\mathrm{NC})_{2} \mathrm{CO}, \mathrm{Cl}_{2} \mathrm{CO}$ and $\mathrm{F}_{2} \mathrm{CO}$ solutes, the most stable isomers of dihydrate complexes have a three-dimensional structure. This is not the case with the $\mathrm{H}_{2} \mathrm{CO}$ and $\mathrm{H}_{2} \mathrm{C}=\mathrm{CO}$ solutes.

These results also indicate that isomers in which the water dimer interacts with the solute are systematically more stable than those in which the two water molecules interact separately with the solute. This means that when trying to maximize the interactions between solute and water dimer, the structures obtained after geometry optimization are more stable than when the starting point is a monohydrated complex and a water molecule. This result is consistent with other work suggesting that solutes with more electrophilic or nucleophilic sites. 
A additional point was observed during these studies: geometry optimizations showed that for four of the five solutes investigated herein, diol isomers are calculated as being significantly more stable than ketone shapes (See Table 5). This point could be of interest to experimenters who would use conditions favourable to the tuning of hydrogen atoms.

\begin{tabular}{|c|c|}
\hline $\mathrm{H}_{2} \mathrm{CO}$ & $\mathrm{Cl}_{2} \mathrm{CO}$ \\
\hline $\begin{aligned} \rho=0.025 \\
\nabla^{2} \rho=0.09 \\
\varepsilon=0.02\end{aligned} \quad \begin{array}{r}\rho=0.35 \\
\nabla^{2} \rho=-2.51 \\
\nabla^{2} \rho=0.0 .49 \\
\varepsilon=0.15\end{array}$ & 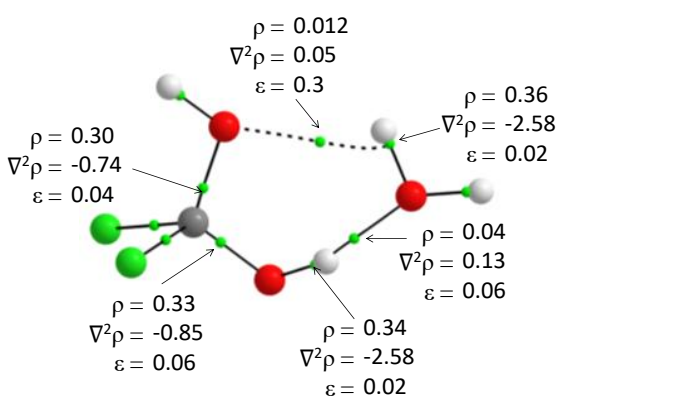 \\
\hline $\mathrm{E}_{\text {int }}=-68.45 \mathrm{~kJ} / \mathrm{mol}$ & $\mathrm{E}_{\text {int }}=-44.18 \mathrm{~kJ} / \mathrm{mol}$ \\
\hline $\mathrm{F}_{2} \mathrm{CO}$ & $\mathrm{H}_{2} \mathrm{C}=\mathrm{CO}$ \\
\hline 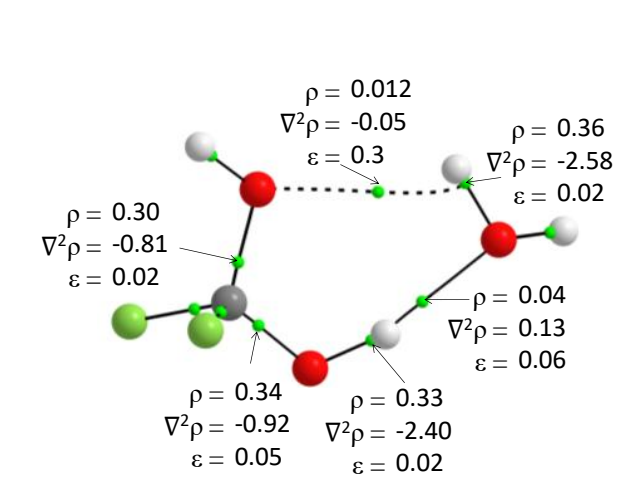 & 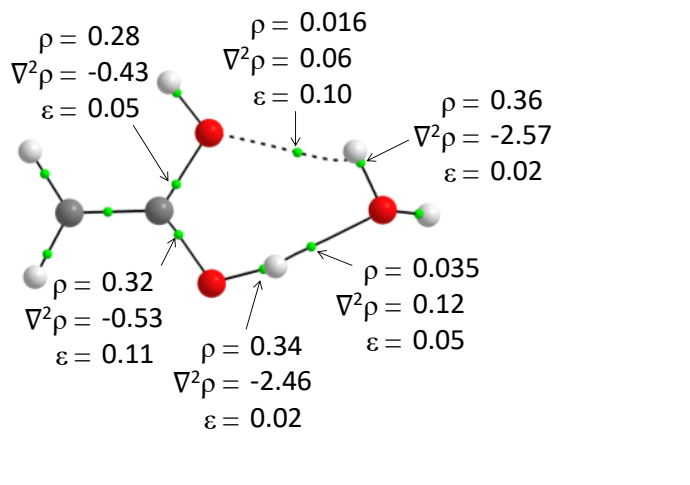 \\
\hline Diol_$W_{1 \_}^{F} 1 \quad \mathrm{E}_{\text {int }}=-77.70 \mathrm{~kJ} / \mathrm{mol}$ & $E_{\text {int }}=-62.51 \mathrm{~kJ} / \mathrm{mol}$ \\
\hline
\end{tabular}

Table 5: Characterization of non-covalent interactions in the different types of diols isomers of the dihydrated complexes obtained after geometry optimization at the LC-wPBE/6-311++G(d,p) level, with GD3BJ correction. The dark lines and the small green spheres are the bond paths and the bond critical points (BCP), respectively. For the intermolecular BCPs, the electron density $\rho$, the Laplacian of the electron density $\nabla^{2} \rho$ and the ellipticity $\varepsilon$ are given. The complexation energy is calculated with respect to the isolated species $\left(\mathrm{E}_{\text {solute }}+2 \times \mathrm{E}_{\mathrm{H} 2 \mathrm{O}}\right)$.

\section{1-3 isomers}

In the case of trihydrated complexes, 16 structures were obtained after geometry optimization. With respect to interactions between water molecules, two families of trihydrated complexes are obtained:

a family in which the water trimer interacts with the solute,

$>$ a family in which one of the three water-water interactions is broken.

Moreover, as far as water-solute interactions are concerned, two main families of trihydrated complexes are also obtained: 
complexes involving both hydrogen bonding interactions and interaction with the solute's $\pi$-hole,

complexes involving only hydrogen bonding interactions.

As in the case of complexes involving a smaller number of water molecules, in addition to these two main families of complexes, two solutes lead to specific water-solute interactions in the trihydrated complexes: $\mathrm{Cl}_{2} \mathrm{CO}$ (halogen bond interactions) and $\mathrm{H}_{2} \mathrm{C}=\mathrm{CO}$ (interaction with the $\pi$-protrusion of the solute). All these families are summarized in Table 6.

\begin{tabular}{|c|c|c|c|}
\hline & & $\begin{array}{l}\text { Cyclic form of water } \\
\text { trimer }\end{array}$ & $\begin{array}{l}\text { Open form of water } \\
\text { trimer }\end{array}$ \\
\hline \multirow{5}{*}{$\begin{array}{l}\text { Interactions with the } \pi \text {-hole and } \\
\text { hydrogen bonding interactions }\end{array}$} & $(\mathrm{NC})_{2} \mathrm{CO}$ & $W_{3}^{N C} 2, \quad W_{3}^{N C} 3$ & $W_{3}^{N C}-1$ \\
\hline & $\mathrm{H}_{2} \mathrm{CO}$ & $W_{3}^{H} 13$ & $W_{3}^{H} 4$ \\
\hline & $\mathrm{F}_{2} \mathrm{CO}$ & $W_{3}^{F} 8$ & $W_{3}^{F} 6_{1}, W_{3}^{F} 7$ \\
\hline & $\mathrm{Cl}_{2} \mathrm{CO}$ & $W_{3}^{C l}=10$ & $W_{3}^{C l} 11$ \\
\hline & $\mathrm{H}_{2} \mathrm{C}=\mathrm{CO}$ & & $W_{3}^{H 2 C}{ }_{14} W_{3}^{H 2 C}{ }_{-18}$ \\
\hline \multirow[t]{5}{*}{ Hydrogen bonding interactions } & $(\mathrm{NC})_{2} \mathrm{CO}$ & & \\
\hline & $\mathrm{H}_{2} \mathrm{CO}$ & & $W_{3}^{H} 5$ \\
\hline & $\mathrm{F}_{2} \mathrm{CO}$ & & \\
\hline & $\mathrm{Cl}_{2} \mathrm{CO}$ & & \\
\hline & $\mathrm{H} \mathrm{H}_{2} \mathrm{C}=\mathrm{CO}$ & $W_{3}^{H 2 C} \_16$ & \\
\hline $\begin{array}{l}\text { Hydrogen bonding and halogen } \\
\text { bonding interactions }\end{array}$ & $\mathrm{Cl}_{2} \mathrm{CO}$ & & $W_{3-}^{C l} 17$ \\
\hline $\begin{array}{l}\text { Interactions with the } \pi \text {-hole, } \\
\text { hydrogen bonding and halogen } \\
\text { bonding interactions }\end{array}$ & $\mathrm{Cl}_{2} \mathrm{CO}$ & $W_{3-}^{C l} 12$ & \\
\hline $\begin{array}{l}\text { Interactions with the } \pi \text {-protrusion } \\
\text { and hydrogen bonding interactions }\end{array}$ & $\mathrm{H}_{2} \mathrm{C}=\mathrm{CO}$ & $W_{3}^{H 2 C} \_15$ & \\
\hline
\end{tabular}

Table 6: Classification of the different $\left(\left(\mathrm{H}_{2} \mathrm{O}\right)_{3}\right.$ :S complexes obtained after geometry optimization, according to the cyclic- or open- shape of the water trimer, and to the nature of the water-solute interactions.

As in the case of mono- and dihydrated complexes, the complexes formed with solute (NC) ${ }_{2} \mathrm{CO}$ are characterized by the highest interaction energies in absolute values (Figure 7 and Table 7).

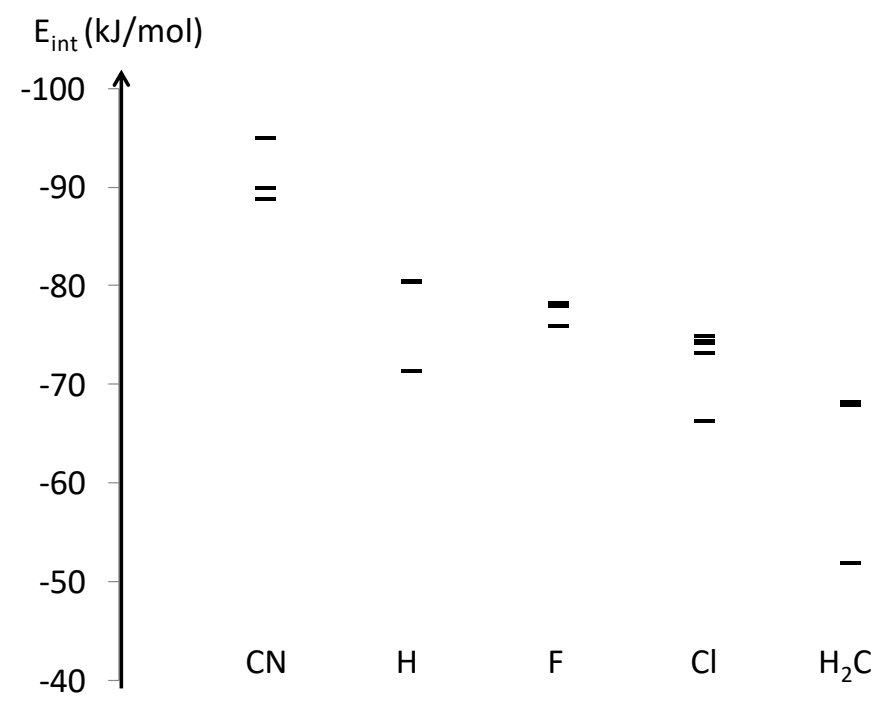


Figure 7: Comparison of the water-solute interaction energies in the most stable $\left(\mathrm{H}_{2} \mathrm{O}\right)_{3}: \mathrm{S}$ isomers obtained after geometry optimization (including ZPE). The water-solute interaction energy is calculated with respect to the sum of three times the energy of an isolated water molecule and the energy of the isolated solute.

Three trihydrated complexes close in energy were obtained after geometry optimization with solute (NC)2CO: $W_{3}^{N C} \_1 \quad\left(\mathrm{E}_{\text {int }}=-95.03 \mathrm{~kJ} / \mathrm{mol}\right.$.), $W_{3}^{N C} \_2 \quad\left(\mathrm{E}_{\text {int }}=-89.97 \mathrm{~kJ} / \mathrm{mol}\right.$.), and $W_{3}^{N C} \_3 \quad\left(\mathrm{E}_{\text {int }}=-88.80\right.$ $\mathrm{kJ} / \mathrm{mol}$.). The QTAIM topological analysis indicates that the dominant water-solute interaction in these three complexes is an interaction involving the $\pi$-hole of the solute. The strong $\pi$-hole present on the isolated $(\mathrm{NC})_{2} \mathrm{CO}$ solute is therefore consistent with the fact that these complexes are associated with high interaction energies.
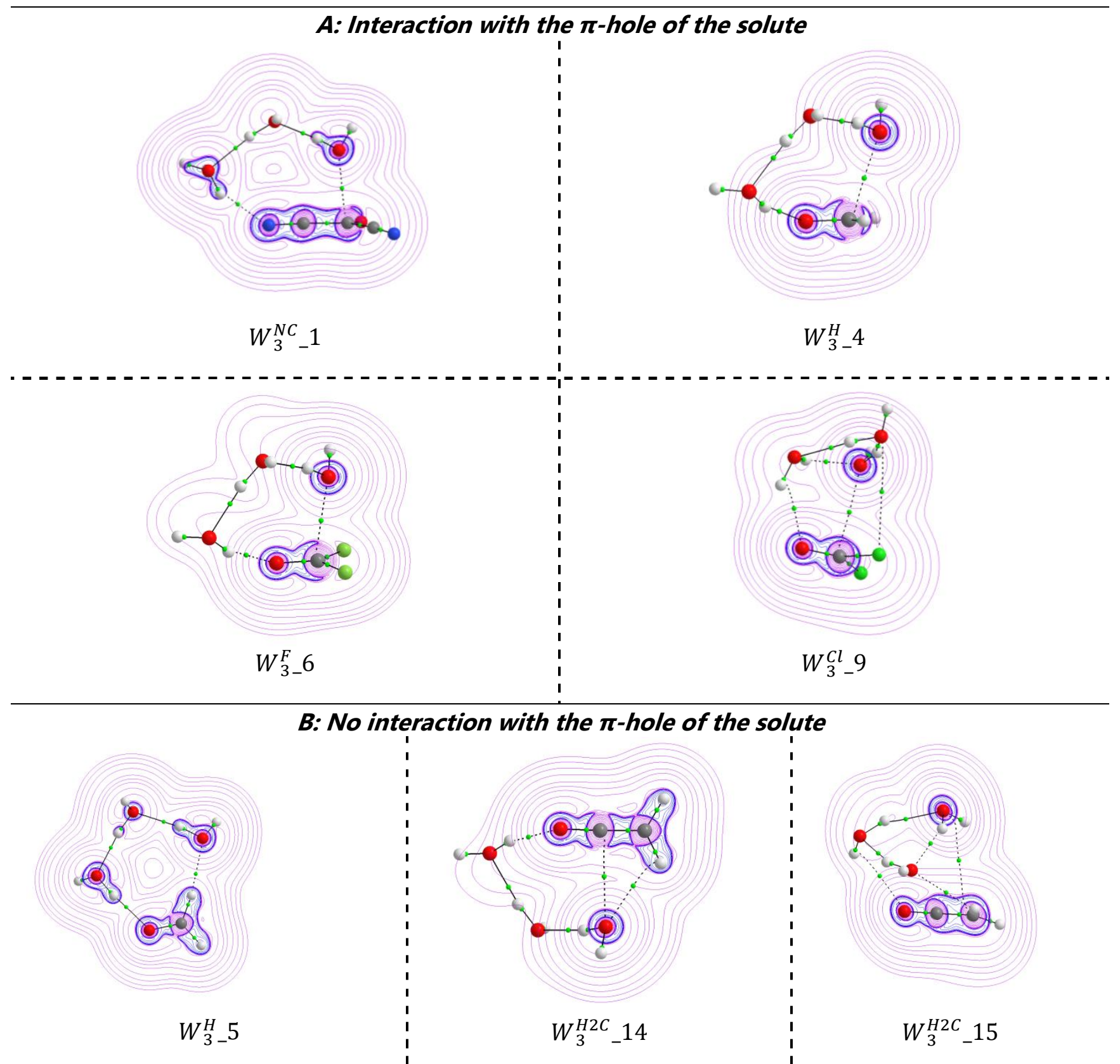

\footnotetext{
Figure 8: A: Contour map of the Laplacian of the electron density $\nabla^{2} \rho$ orthogonally to the plane of the solute for the most stable isomers of trihydrated complexes involving an interaction with the $\pi$-hole of the solute

B: Contour map of the Laplacian of the electron density $\nabla^{2} \rho$ in the plane of the solute for the most stable isomers of trihydrated complexes that do not involve an interaction with the $\pi$-hole of the solute. The blue lines correspond to negative values of $\nabla^{2} \rho$ whereas red lines correspond to positive values of $\nabla^{2} \rho$. The dark lines and the small green spheres are the bond paths and the bond critical points (BCP), respectively.
} 
The most stable structure obtained with $\mathrm{H}_{2} \mathrm{CO}\left(W_{3}^{\mathrm{H}} 4, \mathrm{E}_{\mathrm{int}}=-80.50 \mathrm{~kJ} / \mathrm{mol}\right.$. $)$ appears to be geometrically quite similar to that of the $W_{3}^{N C}{ }_{-} 1$ complex: an open form of the water trimer apparently interacts with a " $\pi$-hole" on the solute, and forms a hydrogen bond with the oxygen atom in the solute. In the absence of a true $\pi$-hole in the vicinity of the carbon atom of the $\mathrm{H}_{2} \mathrm{CO}$ solute, we decided to further investigate the origin of this interaction. The contour maps of the Laplacian of the electron density $\nabla 2 \rho$ shows that one of the oxygen atoms of the water trimer interacts with the electrophilic zone of the solute, as in the case of the $W_{3}^{N C}{ }_{-} 1$ complex (Figure $8 \mathrm{~A}$ ). The water-solute interaction in the $W_{3}^{N C}{ }_{-} 1$ and $W_{3}^{H} 4$ complexes can therefore be considered to be of the same nature. The QTAIM analysis also shows that a similar interaction is found in the most stable trihydrated complexes with $\mathrm{F}_{2} \mathrm{CO}\left(W_{3-}^{F} 6, \mathrm{E}_{\text {int }}=-78.23 \mathrm{~kJ} / \mathrm{mol}\right.$. $)$ and $\mathrm{Cl}_{2} \mathrm{CO}\left(W_{3}^{C l}{ }_{-}, \mathrm{E}_{\mathrm{int}}=-74.93\right.$ $\mathrm{kJ} / \mathrm{mol}$.) (Figure 8A and Table 7).

For the trihydrated $\mathrm{H}_{2} \mathrm{CO}$ complex, an isomer isoenergetic with the $W_{3}^{H} 4$ one was obtained: $W_{3}^{H} 5$. $\left(E_{\text {int }}=-80.42 \mathrm{~kJ} / \mathrm{mol}\right.$.) The QTAIM analysis reveals that this structure leads to the formation of two hydrogen bonds between the water molecules and the solute (Figure $8 \mathrm{~B}$ and Table 7). It is interesting to note that for this solute, both forms with and without interaction with the carbonyl $\pi$ hole $\left(W_{3}^{H} 4\right.$ and $W_{3}^{H}{ }_{-}$, respectively) are isoenergetic.

With the $\mathrm{H}_{2} \mathrm{C}=\mathrm{CO}$ solute, three quasi-isoenergetic isomers were obtained: $W_{3}^{H 2 C}{ }_{-} 14\left(\mathrm{E}_{\mathrm{int}}=-68.26\right.$ $\mathrm{kJ} / \mathrm{mol}), W_{3}^{H 2 C} \_15\left(\mathrm{E}_{\mathrm{int}}=-68.24 \mathrm{~kJ} / \mathrm{mol}\right)$ and $W_{3}^{H 2 C} \_16\left(\mathrm{E}_{\mathrm{int}}=-67.95 \mathrm{~kJ} / \mathrm{mol}\right)$. The QTAIM analysis (Figure $8 \mathrm{~B}$ and Table 7) provides an interpretation of the interactions involved in these complexes:

$>$ for the $W_{3}^{H 2 C}{ }_{-} 14$ isomer, the water trimer is located in the same plane as the solute with which it interacts via the formation of an interaction with the specific $\pi$-hole of this solute, and via two hydrogen bond type interactions,

$>$ in the case of the $W_{3}^{H 2 C}{ }_{-} 15$ isomer, the water trimer interacts with the solute via the formation of an interaction with the specific $\pi$-protrusion of this solute, and via two hydrogen bond interactions.

$>$ and in the case of the $W_{3}^{H 2 C}{ }_{-} 16$ isomer, only hydrogen bond interactions are identified.

Among the most stable isomers shown in Table 7, 5 have a global three-dimensional structure: $W_{3}^{N C}{ }_{1}{ }^{\prime} W_{3_{4^{\prime}}}^{H} W_{3_{6}}^{F} W_{3{ }_{9}}^{C l}$ and $W_{3}^{H 2 C}{ }_{2} 15$. Thus, with each of the solutes considered for this study, a trihydrated isomer with a three-dimensional structure is found among the most stable isomers. Only the $W_{3-}^{H} 5$ and $W_{3}^{H 2 C}{ }_{-} 14$ isomers have a globally planar arrangement of the main atoms.

The other isomers obtained are less favorable in terms of energy; they are presented in Table 7 and in Supporting Information. 


\begin{tabular}{|c|c|c|c|}
\hline & $\mathrm{H}_{2} \mathrm{CO}$ & $\mathrm{Cl}_{2} \mathrm{CO}$ & $\mathrm{F}_{2} \mathrm{CO}$ \\
\hline $\begin{array}{l}\text { Hydrogen } \\
\text { bonding }\end{array}$ & 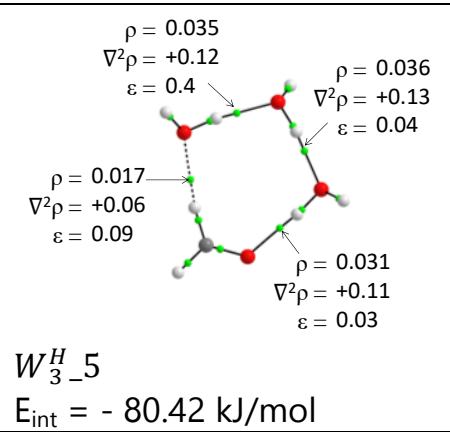 & $\begin{aligned} \rho & =0.031 \\
\nabla^{2} \rho & =+0.12 \\
\varepsilon & =0.05 \\
\rho=0.031 & \end{aligned}$ & \\
\hline \multirow{4}{*}{$\begin{array}{l}\mathrm{n} \rightarrow \pi \\
\text { interactions }\end{array}$} & 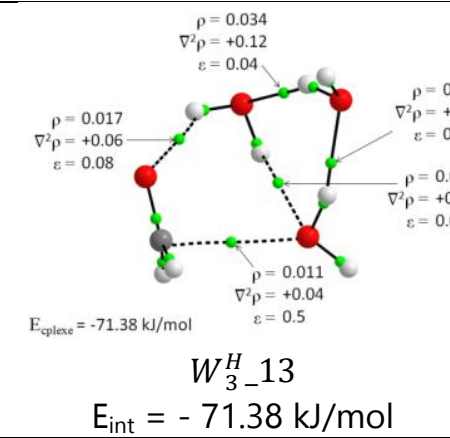 & 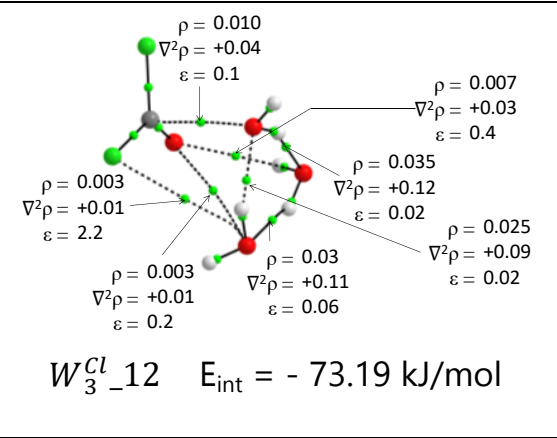 & $\begin{aligned} \rho & =0.031 \\
\nabla^{2} \rho & =+0.11\end{aligned}$ \\
\hline & 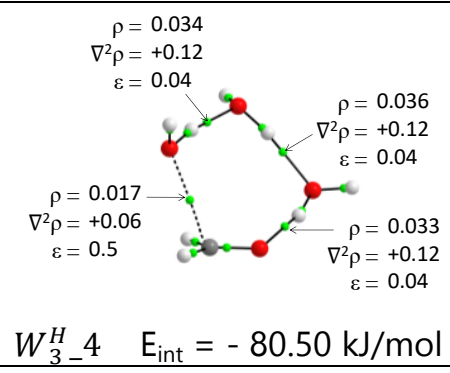 & $\begin{aligned} \rho=0.009 \\
\nabla^{2} \rho=+0.03 \\
\varepsilon=0.3 \\
\rho=0.010 \\
\nabla^{2} \rho=+0.04 \\
\varepsilon=0.3\end{aligned}$ & $W_{3-7}^{F} \mathrm{E}_{\text {int }}=-77.97 \mathrm{~kJ} / \mathrm{mol}$ \\
\hline & & $\begin{aligned} \rho & =0.031 \\
\nabla^{2} \rho & =+0.11 \\
\varepsilon & =0.08\end{aligned}$ & 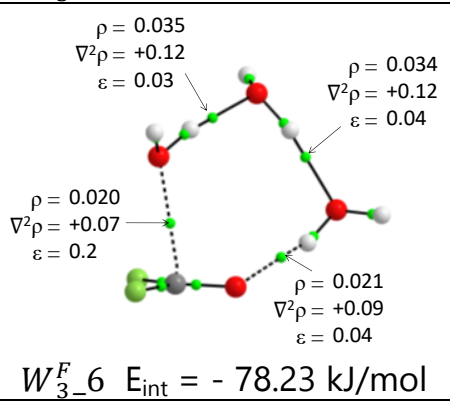 \\
\hline & & $\begin{aligned} \rho & =0.033 \\
\nabla^{2} \rho & =+0.12 \\
\varepsilon & =0.05\end{aligned}$ & \\
\hline
\end{tabular}




\begin{tabular}{|c|c|c|}
\hline & $(\mathrm{NC})_{2} \mathrm{CO}$ & $\mathrm{H}_{2} \mathrm{C}=\mathrm{CO}$ \\
\hline $\begin{array}{l}\text { Hydrogen } \\
\text { bonding }\end{array}$ & $v^{2}$ & $\begin{aligned} \rho=0.029 \\
\nabla^{2} \rho=+0.11 \\
\varepsilon=0.06\end{aligned} \begin{array}{r}\rho=0.031 \\
\nabla^{2} \rho=0.008 \\
\varepsilon=0.3\end{array}$ \\
\hline \multirow{4}{*}{$\begin{array}{l}\mathrm{n} \rightarrow \pi \\
\text { interactions } \\
\text { and } \\
\text { interaction } \\
\text { with a } \pi \\
\text { protrusion }{ }^{a}\end{array}$} & $\begin{aligned} \rho=0.038 \\
\nabla^{2} \rho=+0.13 \\
\varepsilon=0.04 \\
W_{3}^{N C} \_1 \quad E_{\text {int }}=-95.03 \mathrm{~kJ} / \mathrm{mol} \\
\nabla^{2} \rho=+0.08 \\
\varepsilon=0.5\end{aligned}$ & 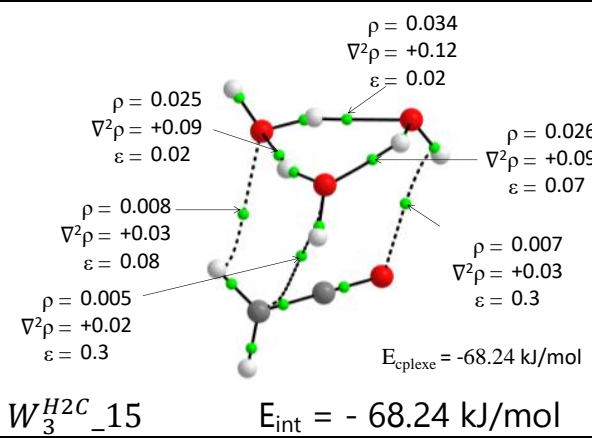 \\
\hline & $\begin{aligned} \rho=0.040 \\
\nabla^{2} \rho=+0.13 \\
\varepsilon=0.02\end{aligned}$ & $\begin{aligned} \rho=0.004 \\
\nabla^{2} \rho=+0.04 \\
\varepsilon=0.13\end{aligned}$ \\
\hline & 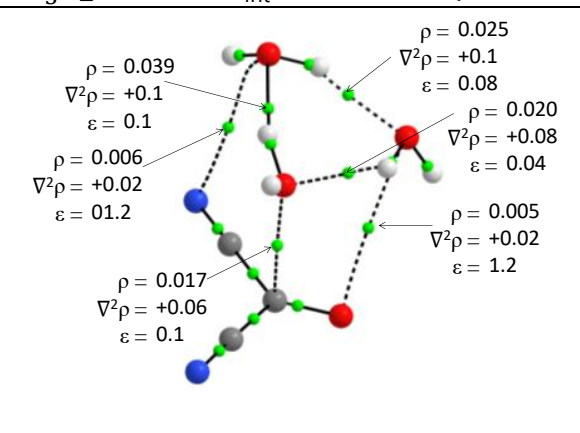 & $\begin{aligned} \rho & =0.012 \\
\nabla^{2} \rho & =0.012 \\
\varepsilon=0.04 & =+0.04\end{aligned}$ \\
\hline & $W_{3}^{N C} \_3 \quad \mathrm{E}_{\mathrm{int}}=-88.80 \mathrm{~kJ} / \mathrm{mol}$ & $W_{3}^{H 2 C} \_18 \quad E_{\text {int }}=-51.95 \mathrm{~kJ} / \mathrm{mol}^{\mathrm{a}}$ \\
\hline
\end{tabular}

Table 7: Characterization of non-covalent interactions in the different types of trihydrated complexes obtained after geometry optimization at the LC-WPBE/6-311++G(d,p) level, with GD3BJ correction. The dark lines and the small green spheres are the bond paths and the bond critical points (BCP), respectively. For the intermolecular BCPs, the electron density $\rho$, the Laplacian of the electron density $\nabla^{2} \rho$ and the ellipticity $\varepsilon$ are given. The complexation energy is calculated with respect to the isolated species $\left(E_{\text {solute }}+3 \times E_{\mathrm{H} 2 \mathrm{O}}\right){ }^{\mathrm{a}}$ : In this complex, a water molecule interacts with the solute via the $\pi$ protrusion located above the carbon hybridised $\mathrm{sp}^{2}$.

It can therefore be seen that the structures of the most stable trihydrated isomers can be partially predicted from the topological analysis of isolated solutes. It should be noted however that the QTAIM topological analysis, including the contour maps of the Laplacian of the electron density $\nabla 2 \rho$, is a good complement to an MESP analysis of isolated carbonyls, particularly for predicting interactions with the $\mathrm{H}_{2} \mathrm{CO}$ solute's $\pi$-hole-like. 
Some of the water-solute interactions involved in these complexes are similar to those involved in mono- and di-hydrate complexes.

\section{1-6 isomers}

After having characterized the smallest microhydrated complexes, we were interested in studying hexahydrated complexes. Indeed, there are different stable isomers energetically close to each other for the $\left(\mathrm{H}_{2} \mathrm{O}\right)_{6}$ complexe: these isomers are often referred to as "prism", "book", "cage" and "cyclic", in reference to their overall shape. Due to its structure, the cage isomer is not the most suitable for the formation of water-solute interactions, and it will not be particularly discussed here. The MESPs of the prism, book and cyclic isomers are presented in Figures 1 and 2, and we systematically looked for hexahydrated isomers formed by interaction of these three complexes with the five solutes herein studied. For comparison, we also looked for isomers obtained by the interaction of two water trimers with the solute. Figure 9 allows to compare the energies of the isomers thus obtained for the different solutes. To identify possible cooperative effects, we have also included in this figure twice the interaction energy of a water trimer with each solute in the most stable trihydrated complexes previously obtained.

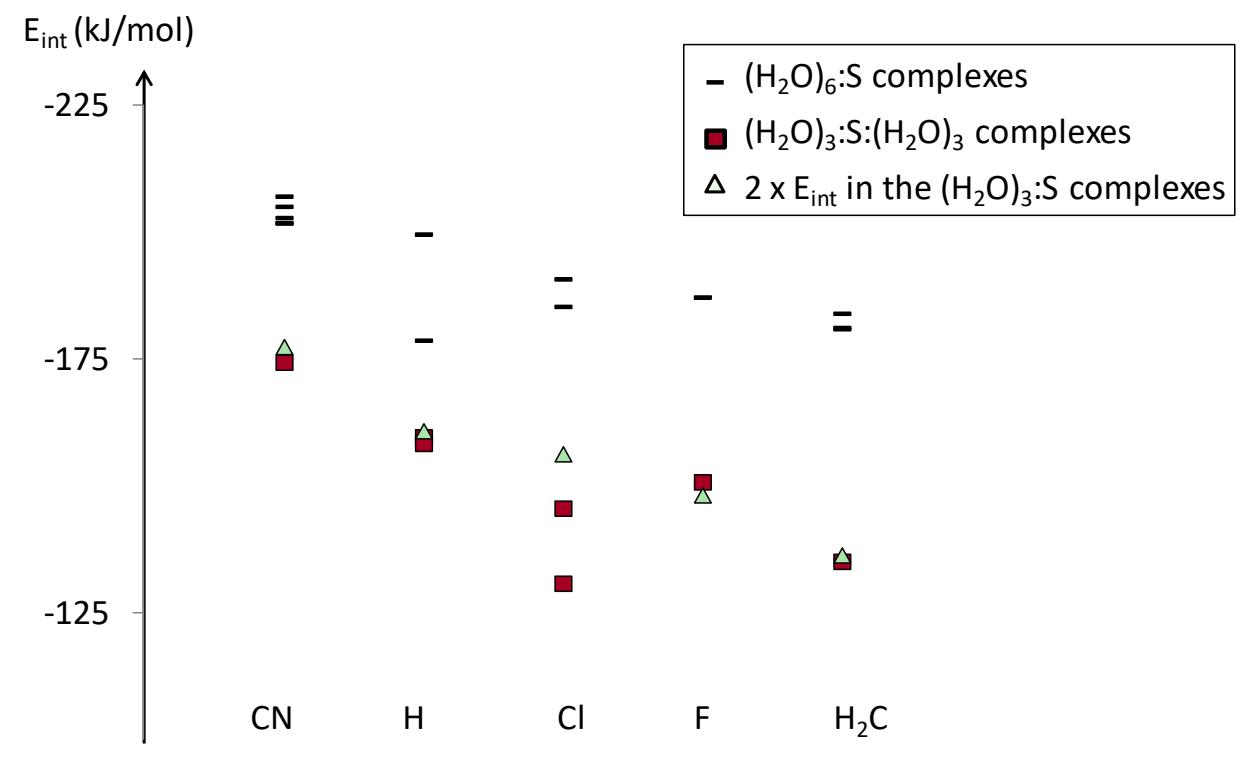

Figure 9: Comparison of the water-solute interaction energies in the most stable $\left(\mathrm{H}_{2} \mathrm{O}\right)_{6}: \mathrm{S}$ and $\left(\mathrm{H}_{2} \mathrm{O}\right)_{3}: \mathrm{S}:\left(\mathrm{H}_{2} \mathrm{O}\right)_{3}$ isomers obtained after geometry optimization (including ZPE). The water-solute interaction energy is calculated with respect to the sum of six times the energy of an isolated water molecule and the energy of the isolated solute.

Figure 9 clearly shows that the most stable isomers are those in which a water hexamer interacts with the solute, rather than those in which two water trimers interact with the solute. In this second case, there is no overall cooperative effect or anticooperative effect identified with respect to the interaction of a single water trimer with the solute: the interaction energies in the $\left(\mathrm{H}_{2} \mathrm{O}\right)_{3}: \mathrm{S}:\left(\mathrm{H}_{2} \mathrm{O}\right)_{3}$ complexes are broadly similar to twice the interaction energy calculated in the corresponding $\left(\mathrm{H}_{2} \mathrm{O}\right)_{3}: \mathrm{S}$ complexes. Figure 9 also shows that, once again, it is with the $(\mathrm{NC})_{2} \mathrm{CO}$ solute that the complexes associated with the highest interaction energies in absolute value are found. Similarly, it is once again with the $\mathrm{H}_{2} \mathrm{C}=\mathrm{CO}$ solute that the complexes associated with the lowest interaction energies are obtained. 


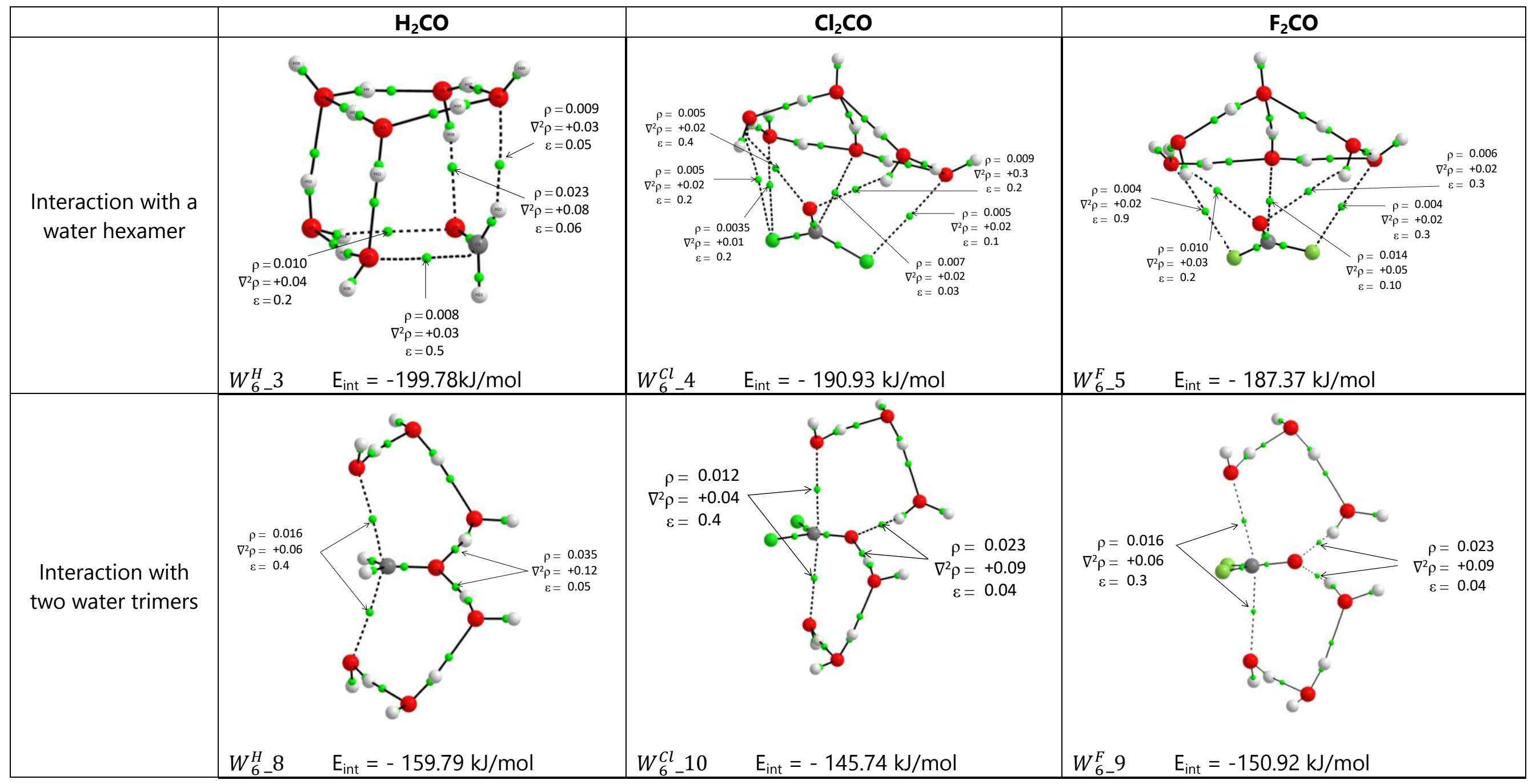




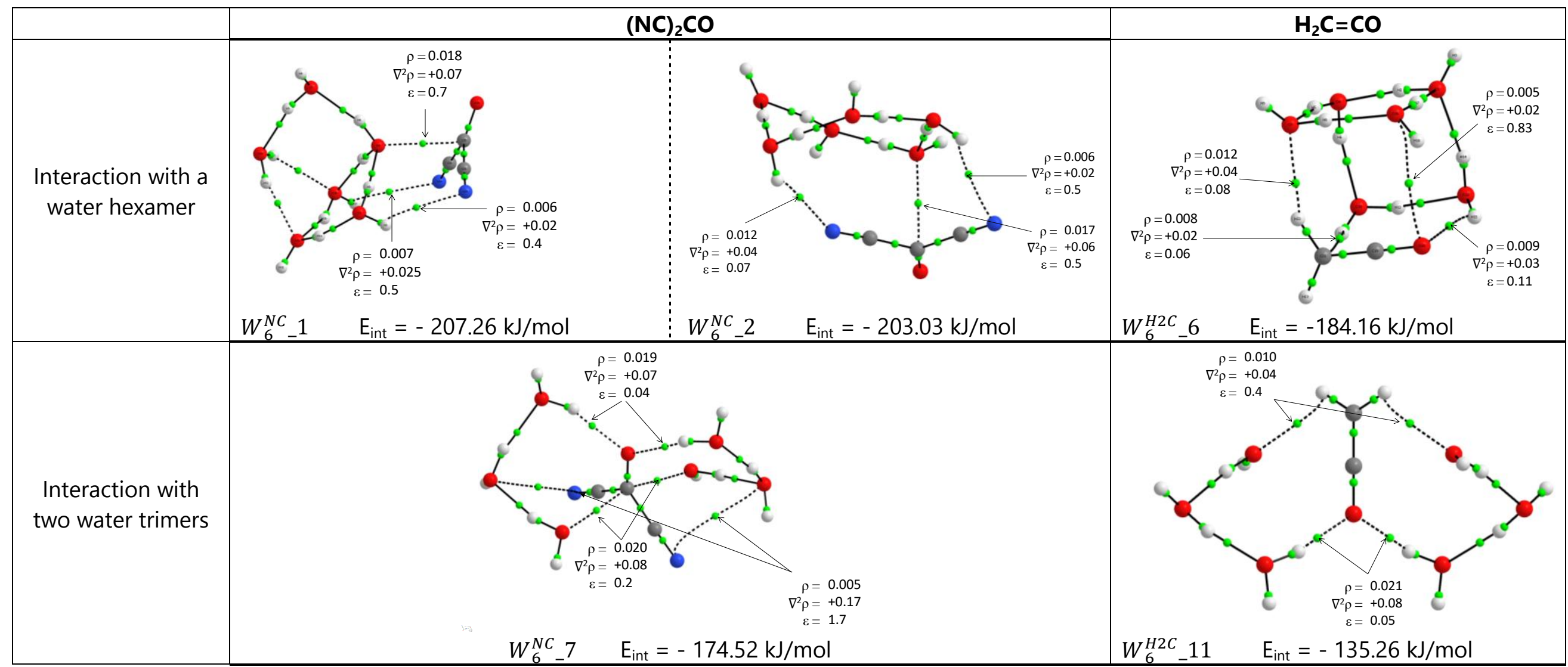

Table 8: Characterization of non-covalent interactions in the different types of hexahydrated complexes obtained after geometry optimization at the LC- $\omega P B E / 6-311++G(d, p)$ level, with GD3BJ correction. The dark lines and the small green spheres are the bond paths and the bond critical points (BCP), respectively. For the water-solute intermolecular BCPs, the electron density $\rho$, the Laplacian of the electron density $\nabla^{2} \rho$ and the ellipticity $\varepsilon$ are given. The complexation energy is calculated with respect to the isolated species $\left(E_{s o l u t e}+6 \times\right.$ $\mathrm{E}_{\mathrm{H} 2 \mathrm{O}) \text {. }}$ 
The most stable isomers in which a water hexamer interacts with the solute are overall 30 to 50 $\mathrm{kJ} / \mathrm{mol}$ more stable than isomers in which two water trimers interact with the solute. This phenomenon is often referred to as "water molecule segregation" in the literature: a single water cluster, in a geometry similar to the most stable isolated water clusters, interacts preferentially with the solute.

The hexahydrated complex leading to the highest interaction energy is $W_{6}^{N C} \_1\left(\mathrm{E}_{\mathrm{int}}=-207.26 \mathrm{~kJ} / \mathrm{mol}\right)$. In this isomer, the $(\mathrm{NC})_{2} \mathrm{CO}$ solute interacts with a water hexamer with the "prism" shape via the formation of an interaction with the $\pi$-hole of the solute (main interaction), and two secondary interactions of the hydrogen bond type, with the $\mathrm{N}$ atoms of the solute. Other isomers of similar energy are obtained with this solute (See Supporting Information), and in particular an isomer in which a "cyclic" water hexamer interacts with the solute: it is the complex $W_{6}^{N C}{ }_{2} 2\left(\mathrm{E}_{\text {int }}=-203.03\right.$ $\mathrm{kJ} / \mathrm{mol})$. This isomer involves the same water-solute interactions as the $W_{6}^{N C}{ }_{-} 1$ isomer: a main interaction with the $\pi$-hole of the solute and two secondary interactions of the hydrogen bond type with the nitrogen atoms of the solute.

In order of decreasing interaction energy in absolute value, the complex $W_{6}^{H} 3$ is then obtained $\left(E_{\text {int }}=-199.78 \mathrm{~kJ} / \mathrm{mol}\right)$. It is a complex in which the $\mathrm{H}_{2} \mathrm{CO}$ solute interacts with a water hexamer with "book" shape via the formation of four water-solute interactions: two hydrogen bond interactions with the solute oxygen atom and one hydrogen bond interaction with one of the solute hydrogen atoms. There is also a secondary interaction with the " $\pi$-hole-like" of the solute. This structure can be considered as an analogue of the water octamer, in which the solute would play the role of two water molecules, as has already been reported in the literature for other solute. ${ }^{46}$

Hexahydrated complexes characterized by similar interaction energies and structures have been obtained with $\mathrm{Cl}_{2} \mathrm{CO}$ and $\mathrm{F}_{2} \mathrm{CO}$ solutes: $W_{6}^{C l} 4 \quad\left(\mathrm{E}_{\text {int }}=-190.93 \mathrm{~kJ} / \mathrm{mol}\right)$ and $W_{6-}^{F} 5 \quad\left(\mathrm{E}_{\mathrm{int}}=-187.37 \mathrm{~kJ} / \mathrm{mol}\right)$. In these structures, it is neither really a "book" shape of the water hexamer, nor really a "cyclic" shape, that is interacting with the solute, but an "intermediate" shape: five water molecules interact with the solute, and the sixth whose nucleophilic properties are not adapted to interact with the solute, is "diverted" from the solute. This phenomenon has already been reported with other solutes, such as $\beta$-propiolactone.

The most stable hexahydrate complex obtained with $\mathrm{H}_{2} \mathrm{C}=\mathrm{CO}$ solute is $W_{6}^{\mathrm{H} 2 \mathrm{C}} \_6\left(\mathrm{E}_{\text {int }}=-184.16 \mathrm{~kJ} / \mathrm{mol}\right)$. It involves an interaction with the $\pi$-protrusion of the solute, and hydrogen bond interactions with a water hexamer in the form of a "book". As in the case of the $W_{6-}^{H} 3$ isomer, this isomer can be interpreted as an analogue of the water octamer, in which the solute would play the role of two water molecules.

\section{Conclusion}

The structures and energies of the $\left(\mathrm{H}_{2} \mathrm{O}\right)_{1,2,2,3,6}: \mathrm{S}$ complexes with the solutes $\mathrm{H}_{2} \mathrm{CO}, \mathrm{F}_{2} \mathrm{CO}, \mathrm{Cl}_{2} \mathrm{CO}$, (NC) ${ }_{2} \mathrm{CO}$ and $\mathrm{H}_{2} \mathrm{C}=\mathrm{CO}$ were identified and characterized from the MESP and QTAIM features of the isolated partners. This preliminary study of isolated solutes allowed to identify a $\pi$-hole at the carbon atom of the carbonyl group for the $\mathrm{F}_{2} \mathrm{CO}, \mathrm{Cl}_{2} \mathrm{CO}$ and $(\mathrm{NC})_{2} \mathrm{CO}$ solutes. In the case of $\mathrm{H}_{2}$ COmolecule, a " $\pi$-hole-like" has been identified: although the MESP does not reach a local maximum perpendicular to the $\mathrm{C}=\mathrm{O}$ bond, the study of the contour maps of the Laplacian of the 
electron density $\nabla 2 \rho$ leads to the identification of an area of low electron density at the carbon atom, which plays an important role for some isomers containing three or six water molecules. The MESP of the $\mathrm{H}_{2} \mathrm{C}=\mathrm{CO}$ solute is significantly different from that of the other four solute solutes considered in this study, with a $\pi$-hole perpedicular to the $\mathrm{C}=\mathrm{O}$ bond but located in the plane of the solute, and a nucleophilic zone located perpendicular to the $\mathrm{C}=\mathrm{C}$ bond, and which we have referred to as " $\pi$-protrusion".

These differences in MESP lead to structurally and energetically very diverse $\left(\mathrm{H}_{2} \mathrm{O}\right)_{1,2,2,3,6}: \mathrm{S}$ isomers:

$>$ the $(\mathrm{NC})_{2} \mathrm{CO}$ solute seems to systematically lead to stronger water-solute interactions than other solute, with a systematic implication of an interaction with the carbonyl $\pi$-hole,

$>$ in the case of $\mathrm{Cl}_{2} \mathrm{CO}$ and $\mathrm{F}_{2} \mathrm{CO}$ solute, the most stable isomers of microhydrated complexes also seem to systematically involve interaction with the carbonyl $\pi$-hole,

$>$ the $\mathrm{H}_{2} \mathrm{CO}$ solute, which does not have a "true" $\pi$-hole, leads instead to isomers involving interactions of the hydrogen bond type in complexes with one or two water molecules. The complex with three water molecules seems to be the size limit above which interactions with the " $\pi$-hole-like" become energetically competitive,

$>$ the $\mathrm{H}_{2} \mathrm{C}=\mathrm{CO}$ solute systematically seems to lead to complexes characterized by the lowest $\mathrm{E}_{\text {int }}$ values (in absolute value).

In conclusion, a precise analysis of the electrophilic and nucleophilic sites of isolated partners seems to be a good starting point for predicting and explaining interactions in water-solute complexes. $\pi$ hole at the carbonyl level strongly affects the structures of the most favourable isomers:

$>$ if this $\pi$-hole is highly electrophilic, it will constitute a privileged interaction site, and will be dominant compared to interactions of the hydrogen or other bonds type that can be formed with water molecules,

$>$ if this $\pi$-hole is weakly marked ( $\pi$-hole-like), there will be an efficient competition between interactions with this site and interactions of the hydrogen bond type.

The most energetically favorable structures depend on all the interaction sites available on the molecule. The most energetically favorable isomers are the ones leading to an overall maximization of interactions between complementary sites with the water clusters.

For all the solute studied here, the most electrophilic and nucleophilic sites available are less reactive than those on the considered water aggregates. This is probably the reason why water molecules preferentially interact with solute as clusters, rather than as isolated water molecules or smaller aggregates: water-water interactions are dominant over water-solute interactions. As soon as three water molecules interact with the solute, three-dimensional structures are the most stable obtained with all solute except $\mathrm{H}_{2} \mathrm{C}=\mathrm{CO}$. The presence of a $\pi$-hole perpendicular to the solute plane seems to be decisive in the formation of these three-dimensional structures. In the case of $\mathrm{H}_{2} \mathrm{C}=\mathrm{CO}$, threedimensional isomers are calculated as being the most stables isomers only in the case of th hexahydrated complex. This $\left(\mathrm{H}_{2} \mathrm{O}\right)_{6}:\left(\mathrm{H}_{2} \mathrm{C}=\mathrm{CO}\right)$ isomer is an analogue of one of the most stable $\left(\mathrm{H}_{2} \mathrm{O}\right)_{8}$ isomers. 
${ }^{1}$ Mo, O., Montero-Campillo, M. M., Alkorta, I., Elguero, J., \& Yañez, M. (2019). Ternary complexes stabilized by chalcogen and alkaline-earth bonds. Crucial role of cooperativity and secondary non-covalent interactions. Chemistry-A European Journal.

${ }^{2}$ Grabowski, S. J. (2013). Non-covalent interactions-QTAIM and NBO analysis. Journal of molecular modeling, 19(11), 4713-4721.

3 Bader, R. F. (2006). Pauli repulsions exist only in the eye of the beholder. Chemistry-A European Journal, 12(10), 2896-2901.

${ }^{4}$ Silvi, B., \& Savin, A. (1994). Classification of chemical bonds based on topological analysis of electron localization functions. Nature, 371(6499), 683.

${ }^{5}$ Savin, A., Nesper, R., Wengert, S., \& Fässler, T. F. (1997). ELF: The electron localization function. Angew. Chem. International Ed., 36(17), 1808-1832.

${ }^{6}$ Silvi, B. (2015). The Relevance of the ELF Topological Approach to the Lewis, Kossel, and Langmuir Bond Model. In The Chemical Bond I/ (pp. 213-247). Springer, Cham.

${ }^{7}$ Gillespie, R. J., \& Robinson, E. A. (2007). Gilbert N. Lewis and the chemical bond: The electron pair and the octet rule from 1916 to the present day. Journal of computational chemistry, 28(1), 87-97.

${ }^{8}$ Remya, K., \& Suresh, C. H. (2015). Non-covalent intermolecular carbon-carbon interactions in polyynes. Physical Chemistry Chemical Physics, 17(40), 27035-27044.

${ }^{9}$ Anjali, B. A., Sayyed, F. B., \& Suresh, C. H. (2016). Correlation and Prediction of Redox Potentials of Hydrogen Evolution Mononuclear Cobalt Catalysts via Molecular Electrostatic Potential: A DFT Study. The Journal of Physical Chemistry A, 120(7), 1112-1119.

${ }^{10}$ Scheiner, S. (2018). Comparison of various means of evaluating molecular electrostatic potentials for noncovalent interactions. Journal of computational chemistry, 3999), 500-510.

${ }^{11}$ Weinhold, F. (2018). Theoretical prediction of robust second-row oxyanion clusters in the metastable domain of antielectrostatic hydrogen bonding. Inorganic chemistry, 57(4), 2035-2044.

12 Bijina, P. V., \& Suresh, C. H. (2016). Molecular electrostatic potential analysis of non-covalent complexes. Journal of Chemical Sciences, 128(10), 1677-1686.

${ }^{13}$ Mohan, N., Suresh, C. H., Kumar, A., \& Gadre, S. R. (2013). Molecular electrostatics for probing lone pair- $\pi$ interactions. Physical Chemistry Chemical Physics, 15(42), 18401-18409.

${ }^{14}$ Gadre, S. R., \& Kumar, A. (2015). Understanding lone pair- $\pi$ interactions from electrostatic viewpoint. In Noncovalent Forces (pp. 391-418). Springer, Cham.

${ }^{15}$ Scheiner, S. (2017). Comparison of halide receptors based on $H$, halogen, chalcogen, pnicogen, and tetrel bonds. Faraday discussions, 203, 213-226.

${ }^{16}$ Adhikari, U., \& Scheiner, S. (2014). Competition between lone pair- $\Pi$, halogen bond, and hydrogen bond in adducts of water with perhalogenated alkenes C2ClnF4- $n(n=0-4)$. Chemical Physics, 440, 53-63.

17 Sánchez-Sanz, G., Trujillo, C., \& Alkorta, I. (2016). Structure, binding energy and chiral discrimination in oxathiirane homodimers. Computational and Theoretical Chemistry, 1090, 171-179.

${ }^{18}$ Kozuch, S. (2016). Should "anion- $\pi$ interactions" be called "anion- $\sigma$ interactions"? A revision of the origin of some hole-bonds and their nomenclature. Physical Chemistry Chemical Physics, 18(44), 30366-30369.

${ }^{19}$ Kirshenboim, O., \& Kozuch, S. (2016). How to twist, split and warp a $\sigma$-hole with hypervalent halogens. The Journal of Physical Chemistry $A, 120(47), 9431-9445$.

${ }^{20}$ Bayat, M., Ebrahimkhani, L., \& Salehzadeh, S. (2016). Where, how and how much the strength of interaction between a hydrated lanthanide cation and a $\pi$-system would be increased? A theoretical study. Journal of Molecular Liquids, 218, 59-67. 
${ }^{21}$ Gadre, S. R., Yeole, S. D., \& Sahu, N. (2014). Quantum chemical investigations on molecular clusters. Chemical reviews, 114(24), 12132-12173.

${ }^{22}$ Murray, J. S., \& Politzer, P. (2017). Molecular electrostatic potentials and noncovalent interactions. Wiley Interdisciplinary Reviews: Computational Molecular Science, 7(6), e1326.

${ }^{23}$ Kalai, C., Zins, E. L., \& Alikhani, M. E. (2017). A theoretical investigation of water-solute interactions: from facial parallel to guest-host structures. Theoretical Chemistry Accounts, 136(4), 48.

${ }^{24}$ Kalai, C., Alikhani, M. E., \& Zins, E. L. (2018). The molecular electrostatic potential analysis of solutes and water clusters: a straightforward tool to predict the geometry of the most stable micro-hydrated complexes of $\beta$-propiolactone and formamide. Theoretical Chemistry Accounts, 137(11), 144.

25 Dargent, D., Zins, E. L., Madebène, B., \& Alikhani, M. E. (2015). Topological insights into the 1/1 diacetyl/water complex gained using a new methodological approach. Journal of molecular modeling, 21(8), 214.

26 Dargent, D., Zins, E. L., Madebène, B., \& Alikhani, M. E. (2016). Energy, structure and topological characterization of the isomers of the 1/2 diacetyl/water complex. Theoretical Chemistry Accounts, 135(2), 32.

${ }^{27}$ Zins, E. L., \& Alikhani, M. E. (2016). Double $\pi$-hole tetrel-chalcogen interactions can lead to stable molecular heterodimer. Molecular Physics, 114(7-8), 1317-1325.

${ }^{28}$ Derbali, I., Zins, E.L., Alikhani, M.E. What is the hydrophobic interaction contribution to the stabilisation of micro-hydrated complexes of trimethylamine oxide (TMAO)? A joint DFT-D, QTAIM and MESP study, Accepted for publication in the Journal, of Molecular Modeling

${ }^{29}$ Murray, J. S., Shields, Z. P. I., Seybold, P. G., \& Politzer, P. (2015). Intuitive and counterintuitive noncovalent interactions of aromatic $\pi$ regions with the hydrogen and the nitrogen of HCN. Journal of Computational Science, 10, 209-216.

${ }^{30}$ Wheeler, S. E., \& Houk, K. N. (2009). Through-space effects of substituents dominate molecular electrostatic potentials of substituted arenes. Journal of chemical theory and computation, 5(9), 2301-2312.

31 Politzer, P., \& Murray, J. S. (2018). The Hellmann-Feynman theorem: a perspective. Journal of molecular modeling, 24(9), 266.

32 Bader, R. F., \& Jones, G. A. (1961). The Hellmann-Feynman theorem and chemical binding. Canadian Journal of Chemistry, 39(6), 1253-1265.

33 Blanco, S., \& López, J. C. (2018). Rotational Characterization of an $n \rightarrow \pi^{*}$ Interaction in a PyridineFormaldehyde Adduct. The Journal of Physical Chemistry Letters, 9(16), 4632-4637.

${ }^{34}$ Pérez, C., Neill, J. L., Muckle, M. T., Zaleski, D. P., Peña, I., Lopez, J. C., Alonso, J.L. \& Pate, B. H. (2015). WaterWater and Water-Solute interactions in Microsolvated Organic Complexes. Angewandte Chemie International Edition, 54(3), 979-982.

${ }^{35}$ Burgi, H. B., Dunitz, J. D., \& Shefter, E. (1973). Geometrical reaction coordinates. II. Nucleophilic addition to a carbonyl group. Journal of the American Chemical Society, 95(15), 5065-5067.

${ }^{36}$ Makuvaza, J. T., Kokkin, D. L., Loman, J. L., \& Reid, S. A. (2019). C-H/ $\pi$ and C-H-O Interactions in Concert: A Study of the Anisole-Methane Complex using Resonant Ionization and Velocity Mapped Ion Imaging. The Journal of Physical Chemistry A, 123(13), 2874-2880.

37 Politzer, P., Murray, J. S., \& Clark, T. (2015). Mathematical modeling and physical reality in noncovalent interactions. Journal of molecular modeling, $21(3), 52$.

${ }^{38}$ Clark, T., Politzer, P., \& Murray, J. S. (2015). Correct electrostatic treatment of noncovalent interactions: the importance of polarization. Wiley Interdisciplinary Reviews: Computational Molecular Science, 5(2), 169-177.

${ }^{39}$ Bader, R. F., Carroll, M. T., Cheeseman, J. R., \& Chang, C. (1987). Properties of atoms in molecules: atomic volumes. Journal of the American Chemical Society, 109(26), 7968-7979. 
40 AlMAll (Version 17.11.14), Todd A. Keith, TK Gristmill Software, Overland Park KS, USA, 2017 (aim.tkgristmill.com)

${ }^{41}$ M. J. Frisch, G. W. Trucks, H. B. Schlegel, G. E. Scuseria, M. A. Robb, J. R. Cheeseman, G. Scalmani, V. Barone, B. Mennucci, G. A. Petersson, H. Nakatsuji, M. Caricato, X. Li, H. P. Hratchian, A. F. Izmaylov, J. Bloino, G. Zheng, J. L. Sonnenberg, M. Hada, M. Ehara, K. Toyota, R. Fukuda, J. Hasegawa, M. Ishida, T. Nakajima, Y. Honda, O. Kitao, H. Nakai, T. Vreven, J. A. Montgomery, Jr., J. E. Peralta, F. Ogliaro, M. Bearpark, J. J. Heyd, E. Brothers, K. N. Kudin, V. N. Staroverov, R. Kobayashi, J. Normand, K. Raghavachari, A. Rendell, J. C. Burant, S. S. lyengar, J. Tomasi, M. Cossi, N. Rega, J. M. Millam, M. Klene, J. E. Knox, J. B. Cross, V. Bakken, C. Adamo, J. Jaramillo, R. Gomperts, R. E. Stratmann, O. Yazyev, A. J. Austin, R. Cammi, C. Pomelli, J. W. Ochterski, R. L. Martin, K. Morokuma, V. G. Zakrzewski, G. A. Voth, P. Salvador, J. J. Dannenberg, S. Dapprich, A. D. Daniels, Ö. Farkas, J. B. Foresman, J. V. Ortiz, J. Cioslowski, and D. J. Fox, Gaussian 09 (Gaussian, Inc., Wallingford CT, 2009).

${ }^{42}$ Vydrov, O. A., Heyd, J., Krukau, A. V., \& Scuseria, G. E. (2006). Importance of short-range versus long-range Hartree-Fock exchange for the performance of hybrid density functionals. The Journal of chemical physics, 125(7), 074106

${ }^{43}$ Grimme, S., Ehrlich, S., \& Goerigk, L. (2011). Effect of the damping function in dispersion corrected density functional theory. Journal of computational chemistry, 32(7), 1456-1465.

${ }^{44}$ Boese, A. D. (2015). Density functional theory and hydrogen bonds: are we there yet?. ChemPhysChem, 16(5), 978-985.

${ }^{45}$ Mardirossian, N., \& Head-Gordon, M. (2017). Thirty years of density functional theory in computational chemistry: an overview and extensive assessment of 200 density functionals. Molecular Physics, 115(19), 23152372.

46 Blanco, S., Pinacho, P., \& López, J. C. (2017). Structure and Dynamics in Formamide-(H2O) 3: A Water Pentamer Analogue. The journal of physical chemistry letters, 8(24), 6060-6066. 